\title{
Consenso | Protocolo Brasileiro para Infecções Sexualmente Transmissíveis 2020: infecção pelo vírus linfotrópico de células T humanas (HTLV)
}

doi: 10.1590/\$1679-497420200006000015.esp1

\author{
Brazilian Protocol for Sexually Transmitted Infections 2020: human T cell lymphotropic \\ virus (HTLV) infection
}

Protocolo Brasileño para Infecciones de Transmisión Sexual 2020: infección por virus linfotrópico de células T humanas (HTLV)

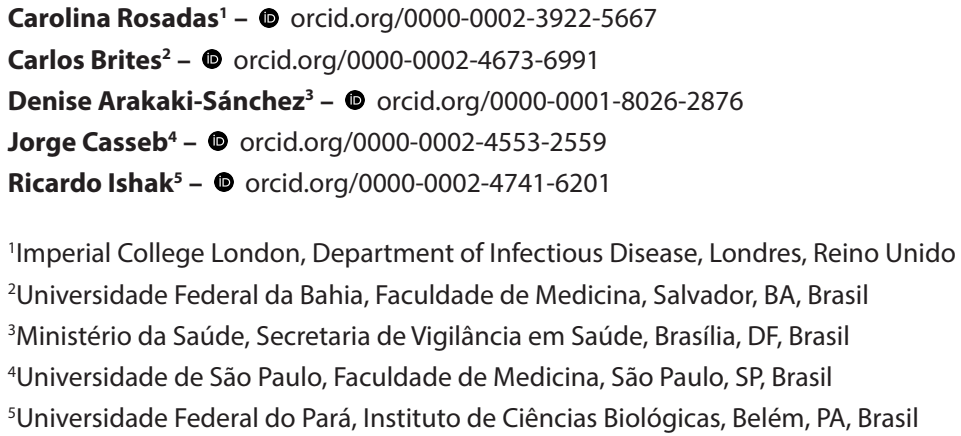

\section{Resumo}

0 artigo aborda a infecção pelo vírus linfotrópico de células T humanas (buman T lymphotropic virus, HTLV), tema contemplado no Protocolo Clínico e Diretrizes Terapêuticas para Atenção Integral às Pessoas com Infecções Sexualmente Transmissíveis, publicado pelo Ministério da Saúde do Brasil. A infecção pelo HTLV-1/2 é um problema de saúde pública mundial, sendo o Brasil o país a referir o maior número de indivíduos convivendo com 0 vírus. 0 HTLV-1 causa diversas manifestações clínicas, de natureza neoplásica, como a leucemia/linfoma de células T do adulto, e de natureza inflamatória, a exemplo da mielopatia associada ao HTLV-1 e outras alterações, como uveíte, artrite e dermatite infecciosa. Estas patologias apresentam elevada morbimortalidade e impactam negativamente a qualidade de vida dos indivíduos infectados. A presente revisão inclui informações relevantes para gestores e profissionais de saúde sobre os mecanismos de transmissão viral, diagnóstico, tratamento e acompanhamento de indivíduos vivendo com o HTLV-1/2 no Brasil.

Palavras-chave: Doenças Sexualmente Transmissíveis; Diagnóstico; Sinais e Sintomas; Prevenção de Doenças.

Endereço para correspondência:

Ricardo Ishak - Universidade Federal do Pará, Instituto de Ciências Biológicas, Laboratório de Virologia, Belém, Pará, Brasil. CEP: $66077-830$

E-mail: rishak@ufpa.br 


\section{Apresentação}

0 artigo aborda a infecção pelo vírus linfotrópico de células T humanas (buman T lymphotropic virus, HTLV), tema que compõe o Protocolo Clínico e Diretrizes Terapêuticas (PCDT) para Atenção Integral às Pessoas com Infecções Sexualmente Transmissíveis (IST), publicado pela Secretaria de Vigilância em Saúde do Ministério da Saúde do Brasil. Para a elaboração do PCDT, realizou-se seleção e análise das evidências disponíveis na literatura e sua discussão, durante um painel de especialistas. 0 documento foi aprovado pela Comissão Nacional de Incorporação de Tecnologias no Sistema Único de Saúde (Conitec), ${ }^{1}$ sendo atualizado pelo grupo técnico de especialistas em IST em $2020{ }^{2}$

\section{A transmissão do HTLV-1/2 pode ocorrer por transfusão de sangue e derivados, uso de drogas injetáveis, transplante de órgãos, relações sexuais desprotegidas e por transmissão vertical.}

\section{Aspectos epidemiológicos}

0 HTLV-1 foi descrito em casos de leucemia/linfoma de adultos e, da mesma forma que o HTLV-2, ${ }^{3-6}$ classificado na família Retroviridae, gênero Deltaretrovirus. ${ }^{7}$ Existem seis subtipos moleculares (a, b, c, d, e, f) do HTLV- $1^{8-10}$ e quatro (a, b, c, d) do HTLV-2:11-14 além de outros dois tipos, HTLV-3 e HTLV-4, estes descritos em áreas isoladas de florestas de Camarões, país da região ocidental da África Central, e ainda não associados a manifestações clínicas. ${ }^{15-17}$

A infecção por HTLV-1/2 resulta da transmissão de linfócitos infectados, presentes em fluidos corpóreos (sangue, sêmen, secreção vaginal e leite materno), por transfusão de sangue e derivados, uso de drogas endovenosas, transplante de órgãos, relações sexuais desprotegidas, e por transmissão vertical. A transmissão vertical pode ocorrer por via placentária e, principalmente, pelo aleitamento materno. ${ }^{18-25} \mathrm{~A}$ carga proviral do HTLV-1 e o tempo de exposição têm relação com o aumento do risco de transmissão, especialmente na relação sexual ou no aleitamento materno. ${ }^{26} 0$ risco associado com a transfusão de sangue e derivados foi significativamente reduzido, com a introdução de triagem sistemática de sangue e órgãos, e pela leucorredução dos componentes sanguíneos. ${ }^{27,28}$

0 contato sexual é uma via importante de disseminação dos vírus HTLV-1 e HTLV-2 em zonas urbanas, rurais e indígenas. ${ }^{12,29,30}$ No meio urbano, a infecção é mais comum entre mulheres, ${ }^{31-33}$ porém, entre c0munidades indígenas, a eficiência de transmissão não mostra diferença entre os sexos. ${ }^{12,29,34} \mathrm{~A}$ transmissão sexual está associada a práticas de sexo desprotegido, parceria sexual com usuário de droga endovenosa e presença de outras IST. ${ }^{35-37}$

0 HTLV-1 e o HTLV-2 distribuem-se em escala mundial. ${ }^{18} 0$ Brasil apresenta frequências variáveis, entre 0,01 e 1,35\% na população geral, ${ }^{28,38,39}$ de acordo com a área geográfica e fatores de risco comportamentais. ${ }^{12,18,40,41}$ Grupos com maior vulnerabilidade à infecção por ambos os vírus incluem (i) os usuários de drogas endovenosas, (ii) os profissionais do sexo, (iii) os homens que fazem sexo com homens, (iv) os indivíduos submetidos a transfusão sanguínea antes de 1993 e (v) os parceiros sexuais sabidamente portadores de HTLV. A diminuição na prevalência do HTLV-1 entre doadores de sangue ao longo dos anos ${ }^{28,38}$ é uma situação privilegiada do Brasil, promovida desde $1993^{42}$ com a regulamentação da obrigatoriedade da triagem do sangue e seus produtos.

Os estudos soroepidemiológicos para HTLV-1/2 baseiam-se na detecção de anticorpos específicos. É importante enfatizar que poucos estudos populacionais foram conduzidos de forma adequada, sendo grande parte da informação epidemiológica sobre HTLV-1/2 decorrente de estudos antigos, os quais, muitas vezes, não definem apropriadamente taxas de incidência e prevalência, mostram resultados conflitantes e não permitem a definição de medidas ajustadas de prevenção e controle. ${ }^{18,39}$

0 HTLV-2, considerado uma infecção ancestral, encontra-se, aparentemente, bem adaptado aos seres humanos, com raras manifestações clínicas. ${ }^{53-48}$ 0 HTLV-2, inclusive, costuma ser utilizado como marcador de migrações humanas, desde a saída das primeiras populações do continente africano. ${ }^{49,50}$

\section{Aspectos clínicos}

Os retrovírus integram-se ao ácido nucleico na célula infectada e estabelecem persistência 
viral, levando à manutenção do vírus e aos diferentes desfechos da infecção. 0 HTLV-1 é associado a um linfoma agressivo, a doença denominada leucemia/ linfoma de células $\mathrm{T}$ do adulto (adult T cell leukemia) lymphoma, ATLL), ${ }^{51,52}$ e a uma doença neurodegenerativa, a mielopatia associada ao HTLV-1 (HTLV-1 associated myelopathy, HAM) ${ }^{53-57}$

A infecção pelo HTLV-1 mostra grande variedade de interações com o hospedeiro humano e já foram reconhecidas manifestações clínicas importantes no olho, ${ }^{58-61}$ pele, ${ }^{61,62}$ pulmão, ${ }^{61,63-65}$ articulações, ${ }^{66-68}$ tireoide, ${ }^{69,70}$ coração $0,{ }^{61,71,72}$ intestino ${ }^{61,73}$ e bexiga ${ }^{61,74,75}$ entre outras. 0 amplo espectro de doenças revela a complexidade clínica da infecção, pelo que requer atenção multidisciplinar no cuidado aos infectados. Não obstante o desfecho clínico das infecções pelo HTLV-1 ser considerado baixo (5\%), o número de casos clínicos associados à infecção pelo HTLV-1 pode alcançar um nível maior, e ainda precisa ser mais bem definido. ${ }^{55}$ Manifestações clínicas intermediárias podem ser frequentes, antes que ocorra a HAM. ${ }^{76,77}$ A carga proviral na infecção pelo HTLV-1 é importante na progressão para doença, ${ }^{78,79}$ e é usualmente baixa nos indivíduos assintomáticos quando comparados àqueles que apresentam doenças relacionadas ao HTLV-1.

\section{Mielopatia associada ao HTLV-1}

A HAM ocorre em cerca de 4\% dos portadores do HTLV, embora manifestações clínicas possam acometer mais de $10 \%$ deles. ${ }^{77}$ A HAM se manifesta, predominantemente, na quarta e na quinta décadas de vida, sendo incomum antes dos 20 ou após os 70 anos de idade. Geralmente, ela tem início insidioso e progride lentamente, sobretudo no sexo feminino: a ocorrência de casos de HAM em mulheres é duas a três vezes superior à observada entre homens. Os distúrbios de marcha são consequentes à diminuição gradual da força muscular e da espasticidade dos membros inferiores,$^{80}$ levando à necessidade, ao longo do tempo, de auxílio para locomoção (com apoio de bengalas e andadores), podendo evoluir para o uso da cadeira de rodas. 0 tempo de evolução varia, de meses a décadas. Os sintomas de disfunção vésico-intestinal e sexual podem ser as queixas iniciais do indivíduo adoecido. Geralmente, a HAM se caracteriza por urge-incontinência urinária, constipação intestinal e disfunção erétil na população masculina. 0 quadro neurológico pode estar associado a processos multissistêmicos, como dermatites, uveítes, pneumonia, além de alterações cognitivas. ${ }^{81,82}$

0 diagnóstico de HAM é deveras importante, seu tratamento precoce pode levar a uma resposta terapêutica mais eficaz ${ }^{83}$ e melhor prognóstico, quando instituído até cinco anos após os primeiros sintomas.

0s níveis de carga proviral correlacionam a progressão da doença especialmente com a fraqueza muscular. Apesar de a magnitude da carga proviral no sangue periférico estar associada a HAM, não é 0 único fator diagnóstico ou prognóstico da patologia. ${ }^{84}$ No líquor, a carga proviral pode ser importante para definir a progressão da HAM, visto que as células infectadas pelo HTLV-1 no sistema nervoso central aceleram o processo inflamatório local. ${ }^{26,85-87}$ Entretanto, outros marcadores de valor prognóstico deveriam ser avaliados, para identificar pessoas sob maior risco de adoecimento. ${ }^{88-90}$

\section{Leucemia/linfoma de células T do adulto}

A neoplasia de células T periféricas causada pelo HTLV-1 apresenta-se com leucocitose, caracteriza-se pela presença de linfócitos anormais (células em flor - flower cells) e, clinicamente, por linfadenopatias, lesões de pele, disfunção de múltiplos órgãos decorrente da invasão das células neoplásicas, além da presença de infecções oportunistas. Elevação dos níveis da enzima lactato desidrogenase e hipercalcemia são características. No Japão, há mais de um milhão de portadores e a incidência de ATLL varia de 0,6 a 0,7 por 1.000 pessoas/ano. ${ }^{91} 0$ risco de adoecimento é maior em homens, e os sintomas têm início 20 a 30 anos após a infecção. ${ }^{92}$ Raramente a ATLL ocorre antes dos 30 anos de idade e tende a aumentar até os 70 anos. Ainda no Japão, onde a probabilidade de desenvolver ATLL é de $5 \%$, são considerados fatores de risco (i) a transmissão materna, (ii) a idade mais avançada, (iii) 0 aumento da carga proviral no sangue periférico, (iv) o histórico familiar de ATLL e (v) 0 teste prévio positivo para anti-HTLV-1. ${ }^{93,94}$ A ATLL é rara em outros países, não chegando a $2 \%$ dos casos, ${ }^{95}$ apesar de evidências da falta de diagnóstico. ${ }^{96,97}$

São reconhecidas quatro formas clínicas da ATLL, ${ }^{98}$ que levam em consideração a presença e a gravidade das manifestações leucêmicas, além de exames laboratoriais alterados, como aumento de lactato desidrogenase e hipercalcemia. Essa classificação é descrita na Figura 1, e os fatores que predizem pior 


\begin{tabular}{|c|c|c|c|c|}
\hline $\begin{array}{l}\text { Classificação e } \\
\text { frequência }\end{array}$ & Manifestações clínicas & $\begin{array}{l}\text { Sobrevida } \\
\text { mediana }\end{array}$ & Diagnóstico & Outros achados \\
\hline \multirow[b]{2}{*}{ Aguda (42 a 47\%) } & $\begin{array}{l}\text { Forma leucêmica, agressiva, leucometria, } \\
\text { linfonodomegalia generalizada. }\end{array}$ & \multirow[b]{2}{*}{6 meses } & \multirow{2}{*}{$\begin{array}{l}\text { Necessita confirmação } \\
\text { histológica se }<5 \% \text { de } \\
\text { linfócitos anormais }\end{array}$} & \multirow{2}{*}{$\begin{array}{l}\text { Hipercalcemia, fraturas, dores ósseas, } \\
\text { exantema cutâneo, elevação de } \\
\text { fosfatase alcalina sem causa aparente }\end{array}$} \\
\hline & $\begin{array}{l}\text { Lesões da pele, ósseas, infiltrados } \\
\text { pulmonares, envolvimento do sistema } \\
\text { nervoso central }{ }^{2}(10 \% \text { dos casos). }\end{array}$ & & & \\
\hline Linfomatosa (19\%) & $\begin{array}{l}\text { Curso rápido, linfadenopatia, } \\
\text { hepatoesplenomegalia, lesões de pele } \\
\text { como exantema eritematoso, pápulas e } \\
\text { nódulos. }\end{array}$ & 10 meses & $\begin{array}{l}\text { Necessita confirmação } \\
\text { histológica se }<5 \% \text { de } \\
\text { linfócitos anormais }\end{array}$ & $\begin{array}{l}\text { Hipercalcemia menos frequente, raras } \\
\text { células tumorais circulantes }\end{array}$ \\
\hline $\begin{array}{l}\text { Crônica (19\%): } \\
\text { favorável (indolente) }\end{array}$ & $\begin{array}{l}\text { Curso lento, exantema cutâneo esfoliativo, } \\
\text { linfocitose absoluta por linfócitos T. }\end{array}$ & 4 anos & $\begin{array}{l}\text { Necessita confirmação } \\
\text { histológica se }<5 \% \text { de } \\
\text { linfócitos anormais }\end{array}$ & $\begin{array}{l}\text { Células em flor podem ser observadas, } \\
\text { lactato desidrogenase aumentada, } \\
\text { hipercalcemia ausente }\end{array}$ \\
\hline Desfavorável & Curso rápido & 15 meses & $\begin{array}{l}\text { Necessita confirmação } \\
\text { histológica se }<5 \% \text { de } \\
\text { linfócitos anormais }\end{array}$ & $\begin{array}{l}\text { Ureia e lactato desidrogenase } \\
\text { aumentadas, albumina diminuída, } \\
\text { células em flor podem ser observadas }\end{array}$ \\
\hline Smoldering (6\%) & $\begin{array}{l}\text { Curso lento, leucometria normal, lesões } \\
\text { de pele e pulmão }\end{array}$ & 4 anos & $\begin{array}{l}\text { Necessita confirmação } \\
\text { histológica se }<5 \% \text { de } \\
\text { linfócitos anormais }\end{array}$ & $\begin{array}{l}\text { Células em flor podem ser observadas } \\
\text { ( } 5 \% \text { ou mais) no sangue periférico, sem } \\
\text { hipercalcemia }\end{array}$ \\
\hline
\end{tabular}

Fonte: adaptado de Nosaka et al. 2017,93 Iwanaga et al. 2010,94 Phillips et al. 2010,95 Rosadas et al. 2020.96

Nota: a) Necessidade de quimioterapia intratecal.

\section{Figura 1 - Classificação e características da leucemia/linfoma de células T do adulto}

prognóstico, incluindo os acima mencionados, encontram-se na Figura 2.51,98-101

\section{Alterações dermatológicas no indivíduo com HTLV}

Além das manifestações clínicas classicamente associadas ao HTLV-1, tais como a dermatite infecciosa e as manifestações cutâneas da ATLL, outras afecções dermatológicas atribuídas à infecção têm sido descritas como formas graves de escabiose (especialmente em coinfectados pelo HIV-1) ${ }^{102}$ ictiose, dermatite seborreica e dermatofitoses. ${ }^{103}$

No início, a dermatite infecciosa foi descrita em crianças jamaicanas infectadas pelo HTLV- $1,{ }^{104}$ principalmente na transmissão vertical, embora a doença também possa afetar adolescentes e adultos. ${ }^{105}$ A dermatite infecciosa se caracteriza por lesões eritemato-descamativas, que atingem principalmente o couro cabeludo, regiões retro-auriculares, pescoço, face, axilas e virilhas. Geralmente, ela está associada à infecção por bactérias Grampositivas, como Streptococcus beta-bemoliticus e Staphylococcus aureus. Segundo um estudo de série de casos demonstrou, quase metade dos indivíduos que tiveram acompanhamento de longo prazo também foram diagnosticados com HAM. ${ }^{106} 0$ diagnóstico diferencial inclui outras causas de eczema crônico, como dermatite atópica e dermatite seborreica. ${ }^{106}$ Presença das lesões características, rinorreia crônica, dermatite crônica recidivante e sorologia positiva para HTLV são os principais critérios para diagnóstico da dermatite infecciosa, cujo tratamento consiste na administração de antibióticos associada com uso tópico de corticosteroides, combinados ou não com antifúngicos.

As alterações dermatológicas na ATLL são bastante variadas (eritrodermia, pápulas, nódulos, lesões infiltrantes ou placas eritematosas) e dependem do estágio da doença; nodulações são mais frequentes nas formas graves, especialmente na forma aguda, linfomatosa, ou cutânea primária tumoral. ${ }^{107}$ As lesões podem ter evolução indolente, e modificar-se com uso de corticosteroides. A avaliação histopatológica é essencial para o diagnóstico específico.

\section{Uveíte no indivíduo com HTLV-1}

No Japão, a uveíte foi relatada pela primeira vez em 1989.$^{108}$ Mais comum em pessoas na idade até 50 anos e um pouco mais frequente em mulheres, sua incidência exata entre portadores de HTLV-1 permanece incerta. 


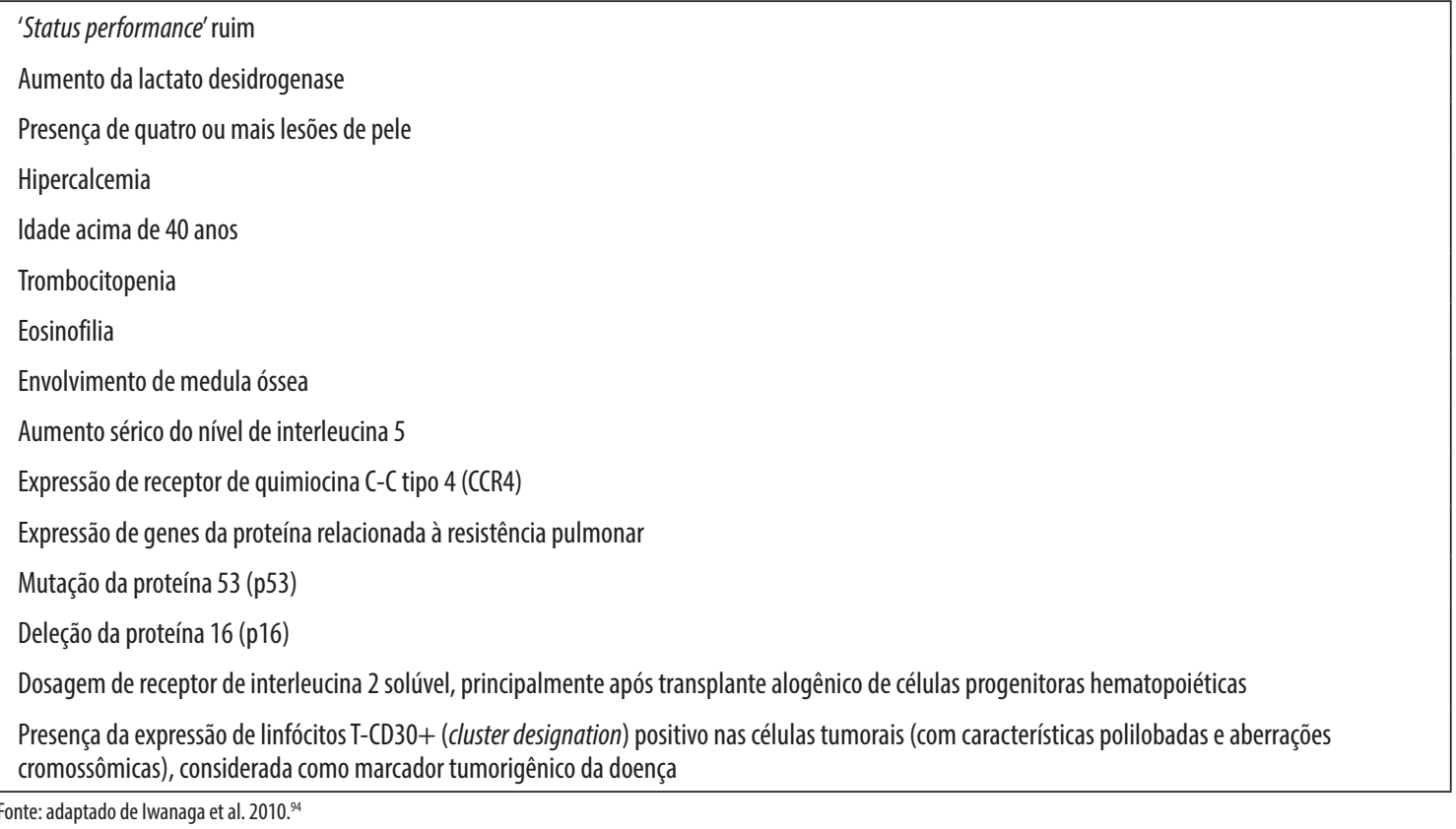

Figura 2 - Fatores de predição de pior prognóstico da leucemia/linfoma de células $T$ do adulto

A doença se manifesta por distúrbios visuais, incluindo 'moscas volantes' e visão embaçada ou nebulosa; e é bilateral em quase metade das pessoas afetadas. ${ }^{109}$ Os sinais oculares incluem: irite; opacidades vítreas; vasculite da retina; e hemorragias e exsudatos da retina. Há uma boa resposta do paciente aos corticosteroides tópicos ou sistêmicos, embora a recidiva seja comum com a descontinuidade da terapia.

\section{Coinfecções no indivíduo com HTLV}

0 indivíduo infectado pelo HTLV pode apresentar algumas coinfecções, com maior frequência que a população geral, seja pelo compartilhamento de vias de infecção, seja como consequência das alterações imunológicas induzidas pela própria infecção. Além disso, o HTLV pode alterar a história natural de algumas infecções, nas situações de coinfecção.

$\mathrm{Na}$ coinfecção pelo HIV, por exemplo, as evidências sugerem um papel neutro ou mesmo protetor para os coinfectados pelo HTLV-2. ${ }^{110}$ Entretanto, se essa coinfecção é provocada pelo HTLV-1, os dados existentes evidenciam maior risco de morte, tanto em adultos como em crianças coinfectadas. ${ }^{111}$ As razões desses achados não são muito claras, sendo uma hipótese explicativa o retardo na introdução da terapia antirretroviral, devido à elevação na contagem de células T-CD4+ causada pelo HTLV-1, sem benefícios clínicos. Indivíduos coinfectados, tratados com antirretrovirais e com supressão da viremia do HIV, apresentam sobrevida similar aos monoinfectados nas mesmas condições; porém, naqueles com carga viral detectável, a sobrevida é significativamente menor para os coinfectados. ${ }^{112}$

Sobre a coinfecção pelo vírus da hepatite $\mathrm{C}$, os dados existentes são conflitantes: enquanto alguns estudos demonstram elevação da viremia do vírus da hepatite $\mathrm{C}$ e menor probabilidade de clearance espontâneo da infecção, ${ }^{113}$ outros sugerem maior chance de eliminação desse vírus em coinfectados pelo HIV e HTLV, provavelmente devido à imunomodulação provocada pelo HTLV nesse grupo de indivíduos, consequente à elevada produção de citocinas pró-inflamatórias. ${ }^{114}$ Ademais, há estudos sugestivos de menor dano hepático em indivíduos triplamente infectados - com o HIV, o HTLV e o vírus da hepatite $\mathrm{C}$ - e maior chance de clearance espontâneo do vírus da hepatite C. ${ }^{115,116}$

Indivíduos portadores de coinfecção HTLV-1 e Strongyloides stercoralis sofrem impacto negativo no curso de ambas as infecções, tornando-se mais susceptíveis a formas mais graves de estrongiloidíase, resistência terapêutica, além de apresentarem maior 


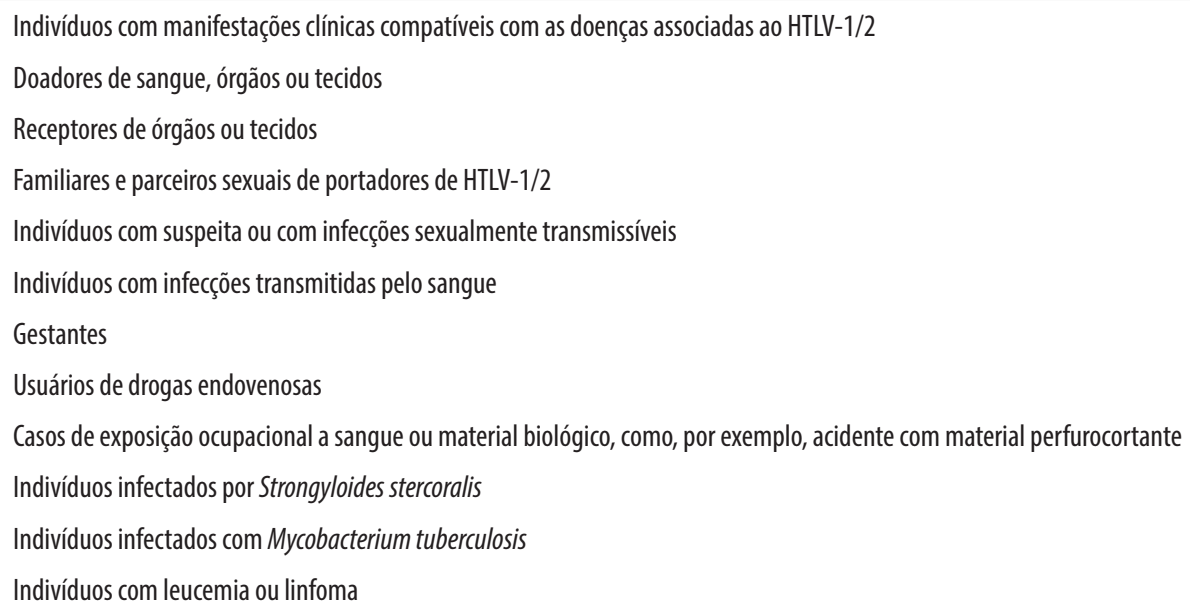

Figura 3 - Indicações de testagem laboratorial para o vírus linfotrópico de células T humanas (HTLV-1/2)

carga proviral do HTLV-1 e maior risco de transmissão vertical do HTLV. ${ }^{117-126}$

Indivíduos com HTLV-1 apresentam maior risco de infecção por Mycobacterium tuberculosis, ${ }^{127-132}$ sendo o impacto clínico dessa coinfecção, todavia, carente de esclarecimento.

\section{Diagnóstico}

No Brasil, a testagem rotineira para HTLV-1/2 em doadores de sangue e de órgãos vem sendo realizada desde 1993 e 2009, respectivamente. ${ }^{42,133} \mathrm{Em}$ ambos os casos, a infecção é critério de exclusão do doador. No Brasil, apesar de não haver uma política nacional de triagem para HTLV-1/2 no pré-natal, o exame é feito como rotina em alguns estados do país. A Portaria MS/SCTIE $n^{0} 23$, de 31 de maio de 2016, incluiu o teste western blot e a reação em cadeia da polimerase (polymerase chain reaction, PCR) para confirmação da infecção pelo HTLV-1 em pessoas com suspeita de ATLL atendidas pelo Sistema Único de Saúde (SUS). ${ }^{134}$ A Figura 3 apresenta as indicações da testagem para HTLV-1/2. 0 diagnóstico laboratorial da infecção deve-se realizar mediante testes de triagem, seguidos de testes confirmatórios em amostra de sangue diferente quando o resultado do teste de triagem for positivo $^{135-137}$ (Figura 4).

Os testes de triagem são usados para deteç̧ão de anticorpos contra HTLV-1/2 no plasma ou soro. As técnicas laboratoriais para a realização desses testes incluem (i) a reação imunoenzimática, (ii) a quimioluminescência e (iii) a aglutinação de partículas. ${ }^{136} 0$ s testes de triagem apresentam elevada sensibilidade e o resultado negativo exclui a infecção - a não ser que haja evidência de exposição recente ao vírus, quando é recomendável repetir o exame após 90 dias. $^{24,25} \mathrm{~A}$ especificidade dos testes de triagem no Brasil varia de 92 a 99,5\%. É recomendada a realização de testes confirmatórios para exclusão de resultados falso-positivos em exame de triagem. . $^{136-138}$

Os testes confirmatórios identificam anticorpos contra diferentes antígenos do HTLV-1 e do HTLV-2, ou amplificam e identificam material genético proviral, geralmente em linfócitos do sangue periférico. São testes confirmatórios e de tipagem viral (i) o western blot, (ii) o imunoensaio em linha (line immuno assay, LIA) e (iii) a PCR. ${ }^{136}$

Habitualmente, o western blot e o LIA são suficientes para o diagnóstico; porém, em alguns casos, pode ocorrer resultado indeterminado ou indefinição quanto ao tipo do HTLV, ${ }^{139-149}$ mais frequentemente em indivíduos infectados pelo HTLV-2 ou HIV-1 ou ambos. ${ }^{141,150} 0$ LIA apresenta maior acurácia na confirmação da infecção por HTLV-1 e HTLV-2, ${ }^{150,151}$ quando comparado ao western blot. ${ }^{150,152}$ Resultados indeterminados ou não tipados pelo western blot ou LIA devem ser submetidos a PCR qualitativo ou quantitativo: são utilizados o nested PCR (nPCR) e a PCR em tempo real (quantitative PCR, qPCR). A RT-PCR permite não só a quantificação da carga proviral de HTLV-1/2, mas também a estratificação do risco de 0 indivíduo desenvolver doenças associadas ao HTLV-1. ${ }^{26,93,94,142,153-155}$ A detecção de RNA viral não é 
utilizada na rotina clínica, uma vez que a viremia é baixa ou ausente, mesmo em indivíduos com HAM. ${ }^{156,157}$

Até o momento desta publicação, um teste molecular para HTLV-1/2 não está disponível comercialmente. 0s testes utilizados são artesanais, sendo necessária validação prévia. ${ }^{15,158-161} \mathrm{~A}$ ausência de testes comerciais e de padronização de protocolos nacionais dificulta a implementação da testagem molecular na rotina e a comparação de resultados obtidos em diferentes laboratórios. ${ }^{162,163}$ Alguns indivíduos infectados pelo HTLV-1/2 podem apresentar carga proviral indetectável. ${ }^{164-166}$ Nestes casos, é possível realizar o nPCR, de maior sensibilidade que o RT-PCR. Outra alternativa está na realização de teste confirmatório sorológico (caso ainda não realizado) ou na solicitação de amostras consecutivas para acompanhamento. ${ }^{148}$
A duração da janela imunológica na infecção por HTLV-1/2 tem-se evidenciado no aparecimento de anticorpos entre 16 e 39 dias após o transplante de órgãos, e o material genético proviral, entre 16 e 23 dias pós-infecção. ${ }^{167}$ Estudo realizado com indivíduos infectados por transfusão sanguínea observou uma mediana de soroconversão de 51 dias (36 a 72 dias). ${ }^{25}$ Convém ressaltar que as metodologias disponíveis quando esse estudo foi desenvolvido não apresentavam a mesma sensibilidade dos métodos diagnósticos atuais. ${ }^{168}$

\section{Tratamento}

A terapia da infecção pelo HTLV-1 consiste em intervenções direcionadas às complicações resultantes da doença. ${ }^{169,170}$ Em 2016, a Conitec, ${ }^{170}$ e em 2019-2020, a

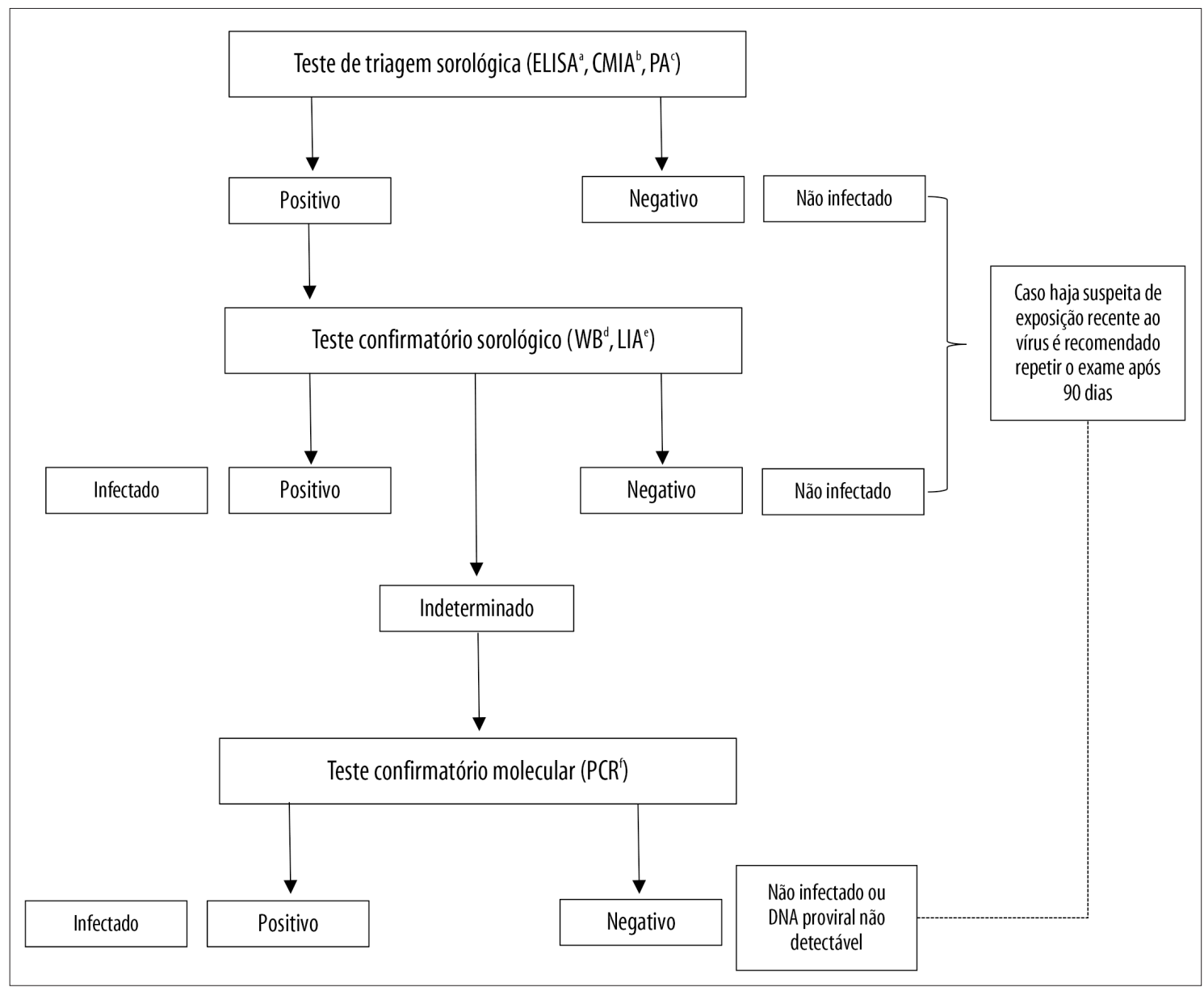

Notas: a) ELISA: ensaio imunoenzimático; b) CMIA: quimioluminescência; c) PA: aglutinação de partículas; d) WB: western blot; e) LIA: imunoensaio em linha; f) P(R: reação em cadeia da polimerase.

Figura 4 - Recomendações para o diagnóstico laboratorial da infecção pelo vírus linfotrópico de células T humanas (HTLV-1/2) 
Sociedade Internacional de Retrovirologia publicaram recomendações para o tratamento de ATLL e HAM. ${ }^{171,172}$ 0 uso da zidovudina associado a interferon alfa foi autorizado para o tratamento de ATLL mediante a publicação da Portaria MS/SVS n ${ }^{0}$ 54, em 18 de julho de 2016. ${ }^{2,170} 0$ os regimes terapêuticos variam de acordo com a apresentação clínica, a progressão dos sintomas e a disponibilidade local dos medicamentos.

As pessoas infectadas devem ser acompanhadas no serviço especializado para receber atendimento de suporte psicológico, com atenção especial para o diagnóstico de manifestações clínicas precoces das diversas manifestações associadas à infecção.

\section{Vigilância, prevenção e controle}

Ainda que tenha sido descrita há algumas décadas, a infecção pelo HTLV permanece relativamente desconhecida pela população geral e por profissionais de saúde. Nos serviços que atendem as pessoas infectadas, a abordagem deve-se focar não apenas nos aspectos relacionados ao risco de adoecimento, ${ }^{173}$ mas também na orientação sobre prevenção da transmissão da doença.

Após um diagnóstico positivo para a infecção pelo HTLV-1/2, os contatos sexuais devem ser convidados a se submeter a triagem sorológica, e aqueles com testes positivos devem ser encaminhados para aconselhamento e seguimento apropriado. Tal aconselhamento deve incluir informações sobre a cronicidade da infecção e a relevância do seguimento clínico de longo prazo. ${ }^{169,174}$ É importante esclarecer as manifestações clínicas iniciais e sua progressão, os mecanismos de transmissão e sua prevenção. A doação de sangue, sêmen, órgãos sólidos ou tecidos não é recomendada, assim como 0 aleitamento materno.

Nos serviços de atendimento a pessoas infectadas pelo HIV e outras IST, é importante incluir o rastreamento do HTLV na rotina do cuidado. 0 indivíduo infectado pelo HTLV deve ser orientado sobre risco de transmissão sexual, parcerias sexuais sorodiscordantes e uso de preservativo - este pode ter seu uso interrompido durante o período fértil, quando houver desejo de engravidar. ${ }^{174}$

No Brasil, dada a escassez de material disponível para os profissionais de saúde e a população geral, várias iniciativas vêm sendo desenvolvidas por grupos acadêmicos e organizações não governamentais para disseminação da informação sobre o HTLV-1/2.
Entre as organizações e iniciativas com esse propósito, destacam-se: o Núcleo de Apoio à Pesquisa em Retrovírus (NAP-Retrovírus) da Universidade de São Paulo; os Cadernos da Fundação Hemominas sobre infecção pelo HTLV; a Associação HTLVida; e o Grupo Vitamóre Associação dos Portadores do HTLV.

A inexistência de um registro nacional de casos prejudica o entendimento do real cenário da infecção no país e, por conseguinte, a implementação de políticas de saúde pública específicas. Cumpre destacar que a notificação de casos é um dos pilares das ações de enfrentamento e pesquisa sobre o HTLV-1 em países como Japão, Inglaterra, Espanha e a ilha de Martinica. ${ }^{175-178}$

\section{Populações especiais}

\section{Gestantes}

No Brasil, a prevalência do HTLV-1/2 em gestantes pode chegar a $1 \%$ em determinadas regiões do país (Tabela 1). ${ }^{159,179-196}$ Apesar da existência de relatos sobre o desenvolvimento de doenças associadas ao HTLV na gestação (HAM, ATLL), não há evidências consistentes sobre o impacto da infecção no ciclo gravídico-puerperal. ${ }^{23}$ Contudo, a infecção na infância está associada a risco aumentado de desenvolvimento de doenças associadas ao HTLV-1, com destaque para a ATLL, esta de elevada letalidade..$^{23,197,198}$ Sendo assim, a prevenção da transmissão vertical é de extrema importância para a redução da incidência de doenças associadas ao vírus. ${ }^{23,96,137}$

Como o aleitamento materno é, sabidamente, a principal via de transmissão vertical do HTLV-1/2 $2^{135,199-204}$ e ainda não existe uma vacina de combate à infecção, sequer tratamento curativo, é contraindicada a amamentação em mães infectadas pelo vírus. Para essas mulheres, recomenda-se 0 uso de inibidores da lactação e o provimento de fórmulas lácteas infantis. ${ }^{2}$ Apesar de a triagem para infecção pelo HTLV-1/2 no pré-natal não estar prevista no SUS, é recomendável a testagem para o vírus em gestantes, seguida de acolhimento para as mulheres infectadas e seus familiares, permitindo a implementação efetiva de medidas de prevenção da transmissão.

\section{Populações indígenas}

As vias de transmissão vertical e sexual são importantes para a manutenção do HTLV em comunidades epidemiologicamente fechadas ou semi fechadas, 
como ocorre com o HTLV-2c, este prevalente entre indígenas residentes na Amazônia brasileira e em áreas urbanas. ${ }^{12,13,205-209}$ Cabe lembrar que a infecção intrafamiliar nas comunidades Kayapó se expressa na transmissão do vírus entre duas ou três gerações, e em mais de $20 \%$ das crianças com menos de 9 anos infectadas. ${ }^{12} \mathrm{~A}$ transmissão vertical mantém 0 vírus em alta endemicidade, uma vez que os procedimentos usuais de não amamentação por mães infectadas,comumente,nãosãoobedecidos. ${ }^{205}$ 0aumento das evidências de doenças associadas ao HTLV-25,43-48 requer atenção especial às comunidades indígenas localizadas em áreas de alta endemicidade do vírus, na Amazônia brasileira. ${ }^{39}$

\section{Conclusões}

Apesar de a infecção pelo HTLV ser negligenciada, o Brasil conta com iniciativas direcionadas ao enfrentamento da infeção e doença pelo HTLV-1. Os agravos com consequências clínicas relevantes, como a mielopatia associada a HTLV-1 e a leucemia/linfoma de células T, podem ser minorados com 0 acesso aos serviços no SUS. Os casos de baixa complexidade podem ser

\section{Tabela 1 - Prevalência da infecção pelo HTLV-1/2 em gestantes, em diferentes estados do Brasil}

\begin{tabular}{|c|c|c|c|}
\hline Região/Estado & Prevalência (\%) & $\mathbf{n}$ & Referência ${ }^{a}$ \\
\hline \multicolumn{4}{|l|}{ Norte } \\
\hline \multirow{2}{*}{ Pará } & 0,6 & 324 & Guerra et al. $2018^{188 b}$ \\
\hline & 0,3 & 13.382 & Sequeira et al. $2012^{192}$ \\
\hline Amazonas & 0 & 674 & Machado Filho et al. $2010^{194}$ \\
\hline \multicolumn{4}{|l|}{ Nordeste } \\
\hline Alagoas & 0,2 & 54.813 & Moura et al. $2015^{179}$ \\
\hline \multirow{5}{*}{ Bahia } & 0,14 & 692 & Boa-Sorte et al. $2014^{190 \mathrm{c}}$ \\
\hline & 1,05 & 2.766 & Mello et al. $2014^{191}$ \\
\hline & 0,98 & 408 & Magalhães et al. $2008^{195}$ \\
\hline & 0,84 & 6.754 & Bittencourt et al. $2001^{183}$ \\
\hline & 0,88 & 1.024 & Santos et al. $1995^{185}$ \\
\hline \multirow{2}{*}{ Maranhão } & 0,7 & 713 & Mendes et al. $2020^{186}$ \\
\hline & 0,3 & 2.044 & Guimarães de Souza et al. $2012^{193}$ \\
\hline Ceará & 0,12 & 814 & Broutet et al. $1996^{184}$ \\
\hline \multicolumn{4}{|l|}{ Centro-0este } \\
\hline \multirow{2}{*}{ Mato Grosso do Sul } & 0,13 & 116.689 & Dal Fabbro et al. $2008^{196}$ \\
\hline & 0,1 & 32.512 & Figueiró Filho et al. $2007^{180}$ \\
\hline Goiás & 0,1 & 15.485 & Oliveira et al. $2006^{181}$ \\
\hline \multicolumn{4}{|l|}{ Sudeste } \\
\hline \multirow{2}{*}{ Rio de Janeiro } & 0,74 & 1.628 & Barmpas et al. $2019^{187}$ \\
\hline & 0,66 & 1.204 & Monteiro et al. $2014^{189}$ \\
\hline São Paulo & 0,1 & 913 & Olbrich Neto et al, $2004^{182}$ \\
\hline \multicolumn{4}{|l|}{ Sul } \\
\hline Paraná & 0,31 & 643 & Medeiros et al. 2018 ${ }^{159 d}$ \\
\hline
\end{tabular}

Notas: a) Foram incluídos apenas estudos com testes confirmatórios para infecção pelo HTLV-1/2; b) Gestantes adolescentes; c) Estudo com amostras de sangue em papel-filtro; d) Gestantes de alto risco. 
acompanhados nos centros de saúde e, quando necessário, encaminhados aos centros especializados, para tratamento, reabilitação e apoio social. A despeito das graves consequências que a infecção possa acarretar à vida das pessoas, seu controle ainda representa um desafio para a saúde pública. Estudos epidemiológicos nacionais, desenvolvimento de testes diagnósticos comerciais e protocolos clínicos com novas opções terapêuticas podem contribuir para a definição de políticas públicas e ações específicas na abordagem, prevenção, controle e tratamento adequados da infecção pelo HTLV-1/2 no Brasil.

\section{Referências}

1. Ministério da Saúde (BR). Portaria MS/SCTIE no 42, de 5 de outubro de 2018. Torna pública a decisão de aprovar o Protocolo Clínico e Diretrizes Terapêuticas para Atenção Integral às Pessoas com Infecções Sexualmente Transmissíveis (IST), no âmbito do Sistema Único de Saúde - SUS [Internet] Diário Oficial da União, Brasília (DF), 2018 out 8 [citado 2020 out 15]; Seção I:88. Disponível em: https://www.in.gov.br/materia/-/asset_publisher/ Kujrw0TZC2Mb/content/id/44303574/do1-2018-1008-portaria-n-42-de-5-de-outubro-de-2018-44303438

2. Ministério da Saúde (BR). Protocolo clínico e diretrizes terapêuticas para atenção integral às pessoas com infeções sexualmente transmissíveis (IST) [Internet]. Brasília: Ministério da Saúde; 2020 [citado 2020 jun 14]. Disponível em: http://www.aids.gov.br/pt-br/ pub/2015/protocolo-clinico-e-diretrizes-terapeuticas-para-atencao-integral-pessoas-com-infeccoes

3. Poiesz BJ, Ruscetti FW, Gazdar AF, Bunn PA, Minna JD, Gallo RC. Detection and isolation of type $\mathrm{C}$ retrovirus particles from fresh and cultured lymphocytes of a patient with cutaneous T-cell lymphoma. Proc Natl Acad Sci U S A [Internet]. 1980 Dec [cited 2020 0ct 15]; 77(12):7415-9. Available from: https://doi.org/10.1073/pnas.77.12.7415

4. Poiesz BJ, Ruscetti FW, Reitz MS, Kalyanaraman VS, Gallo RC. Isolation of a new type $\mathrm{C}$ retrovirus (HTLV) in primary uncultured cells of a patient with Sézary T-cell leukaemia. Nature [Internet]. 1981 Nov [cited 2020 0ct 15]; 294:268-71. Available from: https://doi.org/10.1038/294268a0

\section{Contribuição dos autores}

Rosadas C, Brites C, Arakaki-Sanchez D, Casseb J e Ishak $\mathrm{R}$ contribuíram com a concepção, delineamento, redação e revisão crítica do manuscrito. Todos os autores aprovaram a versão final do manuscrito e são responsáveis por todos os aspectos do trabalho, incluindo a garantia de sua precisão e integridade.

\section{Agradecimento}

Aos membros do grupo técnico de especialistas responsáveis pela elaboração do PCDT para Atenção Integral às Pessoas com IST em 2020.

5. Kalyanaraman VS, Sarngadharan MG, Robert-Guroff M, Miyoshi I, Golde D, Gallo RC. A new subtype of human T-cell leukemia virus (HTLV-II) associated with a T-cell variant of hairy cell leukemia. Science [Internet]. 1982 Nov [cited 2020 0ct 15]; 218(4572):571-3. Available from: https://doi.org/10.1126/science.6981847

6. Gallo RC. History of the discoveries of the first human retroviruses: HTLV-1 and HTLV-2. Oncogene [Internet]. 2005 Sep [cited 2020 0ct 15]; 24(39):5926-30. Available from: https://doi.org/10.1038/sj.onc.1208980

7. International Commitee on Taxonomy of Viruses - ICTV. Taxonomy history: primate T-lymphotropic virus 1 [Internet]. [S.l.]: ICTV; 2017 [cited 2020 0ct 15]. Available from: https://talk. ictvonline.org/taxonomy/p/taxonomy-history?taxnode_id=19911434\&src=NCBI\&ictv_id=19911434

8. Miura T, Fukunaga T, Igarashi T, Yamashita M, Ido E, Funahashi S, et al. Phylogenetic subtypes of human T-lymphotropic virus type I and their relations to the anthropological background. Proc Natl Acad Sci U S A [Internet]. 1994 Feb [cited 2020 0ct 15]; 91(3):1124-7. Available from: https://doi.org/10.1073/pnas.91.3.1124

9. Vidal AU, Gessain A, Yoshida M, Mahieux R, Nishioka K, Tekaia F, et al. Molecular epidemiology of HTLV type I in Japan: evidence for two distinct ancestral lineages with a particular geographical distribution. AIDS Res Hum Retroviruses [Internet]. 1994 Nov [cited 2020 0ct 15]; 10(11):1557-66. Available from: https://doi.org/10.1089/aid.1994.10.1557 
10. Van Dooren S, Salemi M, Vandamme AM. Dating the origin of the African human T-cell lymphotropic virus type-i (HTLV-I) subtypes. Mol Biol Evol [Internet]. 2001 Apr [cited 2020 0ct 15]; 18(4):661-71. Available from: https://doi. org/10.1093/oxfordjournals.molbev.a003846

11. Hall WW, Takahashi H, Liu C, Kaplan MH, Ijichi $\mathrm{S}$, Nagashima K, et al. Multiple isolates and characteristics of human T-cell leukemia virus type II. J Virol [Internet]. $1992 \mathrm{Apr}$ [cited 2020 0ct 15]; 66(4):2456-63. Available from: https://www. ncbi.nlm.nih.gov/pmc/articles/PMC289041/

12. Ishak R, Harrington WJ, Azevedo VN, Eiraku N, Ishak M0, Guerreiro JF, et al. Identification of human T cell lymphotropic virus type IIa infection in the Kayapo, an indigenous population of Brazil. AIDS Res Hum Retroviruses [Internet]. 1995 Jul [cited 2020 0ct 15]; 11(7):813-21. Available from: https://doi.org/10.1089/aid.1995.11.813

13. Eiraku N, Novoa P, Costa Ferreira M, Monken C, Ishak R, Costa Ferreira 0, et al. Identification and characterization of a new and distinct molecular subtype of human T-cell lymphotropic virus type 2. J Virol [Internet]. 1996 Mar [cited 2020 0ct 15]; 70(3):1481-92. Available from: https://www. ncbi.nlm.nih.gov/pmc/articles/PMC189969/

14. Vandamme AM, Salemi M, Van Brussel M, Liu HF, van Laethem K, van Ranst M, et al. African origin of human T-lymphotropic virus type 2 (HTLV-2) supported by a potential new HTLV-2d subtype in Congolese Bambuti Efe Pygmies. J Virol [Internet]. 1998 May [cited 2020 0ct 15]; 72(5):4327-40. Available from: https:/www.ncbi.nlm.nih.gov/pmc/articles/PMC109663/

15. Wolfe ND, Heneine W, Carr JK, Garcia AD, Shanmugam $\mathrm{V}$, Tamoufe U, et al. Emergence of unique primate T-lymphotropic viruses among central African bushmeat hunters. Proc Natl Acad Sci U S A [Internet]. 2005 May [cited 2020 0ct 15]; 102(22):7994-9. Available from: https://doi.org/10.1073/pnas.0501734102

16. Perzova R, Benz P, Abbott L, Welch C, Thomas A, Ghoul RW, et al. Short communication: no evidence of HTLV-3 and HTLV-4 infection in New York State subjects at risk for retroviral infection. AIDS Res Hum Retroviruses [Internet]. 2010 Nov [cited 2020 0ct 15]; 26(11):1229-31. Available from: https://doi.org/10.1089/aid.2010.0079

17. Duong YT, Jia H, Lust JA, Garcia AD, Tiffany AJ, Heneine W, et al. Short communication: Absence of evidence of HTLV-3 and HTLV- 4 in patients with large granular lymphocyte (LGL) leukemia. AIDS Res Hum Retroviruses [Internet]. 2008 Dec [cited 2020 0ct 15]; 24(12):1503-5. Available from: https://doi.org/10.1089/aid.2008.0128

18. Gessain A, Cassar 0. Epidemiological aspects and world distribution of HTLV-1 infection. Front Microbiol [Internet]. 2012 Nov [cited 2020 0ct 15]; 3:388. Available from: https:// dx.doi.org/10.3389\%2Ffmicb.2012.00388

19. Ishak R, Vallinoto ACR, Azevedo VN, Lewis M, Hall WW, Ishak MOG. Molecular evidence of mother-to-child transmission of HTLV-IIc in the Kararao Village ( Kayapo ) in the Amazon Region of Brazil. Rev Soc Bras Med Trop [Internet]. 2001 [cited 2020 Oct 15]; 34(6):519-25. Available from: https:// doi.org/10.1590/S0037-86822001000600004

20. Moriuchi M, Moriuchi H. Seminal fluid enhances replication of human T-cell leukemia virus type 1: implications for sexual transmission. J Virol [Internet]. 2004 Nov [cited 2020 0ct 15]; 78(22):12709-11. Available from: https://dx.doi. org/10.1128\%2FJVI.78.22.12709-12711.2004

21. Lairmore MD, Anupam R, Bowden N, Haines R, Haynes RAH, Ratner L, et al. Molecular determinants of human T-lymphotropic virus type 1 transmission and spread. Viruses [Internet]. 2011 Jul [cited 2020 Oct 15]; 3(7):1131-65. Available from: https://dx.doi.org/10.3390\%2Fv3071131

22. Mendoza C, Roc L, Benito R, Reina G, Ramos JM, Gómez C, et al. HTLV-1 infection in solid organ transplant donors and recipients in Spain. BMC Infect Dis [Internet]. 2019 Aug [cited 2020 0ct 15]; 19:706. Available from: https://doi.org/10.1186/s12879-019-4346-Z

23. Rosadas C, Taylor GP. Mother-to-child HTLV-1 transmission: unmet research needs. Front Microbiol [Internet]. 2019 May [cited 2020 0ct 15]; 10:999. Available from: https://doi.org/10.3389/fmicb.2019.00999

24. Cook LBM, Melamed A, Demontis MA, Laydon DJ, Fox JM, Tosswill JHC, et al. Rapid dissemination of human T-lymphotropic virus type 1 during primary infection in transplant recipients. Retrovirology [Internet]. 2016 Jan [cited 2020 0ct 15]; 13:3. Available from: https://doi.org/10.1186/s12977-015-0236-7

25. Manns A, Wilks RJ, Murphy EL, Haynes G, Barnett M, Hanchard B, et al. A prospective study of transmission by transfusion of HTLV-I and risk factors associated with seroconversion. Int J Cancer [Internet]. 1992 Jul [cited 2020 Oct 15]; 51(6):886-91. Available from: https://doi.org/10.1002/ijc.2910510609 
26. Nagai M, Usuku K, Matsumoto W, Kodama D, Takenouchi N, Moritoyo T, Hashiguchi S, et al. Analysis of HTLV-I proviral load in $202 \mathrm{HAM} / \mathrm{TSP}$ patients and 243 asymptomatic HTLV-I carriers: high proviral load strongly predisposes to HAM/ TSP. J Neurovirol [Internet]. 1998 Dec [cited 2020 0ct 15]; 4(6):586-93. Available from: https://doi.org/10.3109/13550289809114225

27. Dias-Bastos MR, Oliveira CDL, Carneiro-Proietti ABF. Decline in prevalence and asymmetric distribution of human T cell lymphotropic virus 1 and 2 in blood donors, State of Minas Gerais, Brazil, 1993 to 2007. Rev Soc Bras Med Trop [Internet]. 2010 Nov-Dec [cited 2020 0ct 15]; 43(6):615-9. Available from: https://doi.org/10.1590/S0037-86822010000600002

28. Carneiro-Proietti ABF, Sabino EC, Leão S, Salles NA, Loureiro P, Sarr M, et al. Human T-lymphotropic virus type 1 and type 2 seroprevalence, incidence, and residual transfusion risk among blood donors in Brazil during 2007-2009. AIDS Res Hum Retroviruses [Internet]. 2012 0ct [cited 2020 0ct 15]; 28(10):1265-72. Available from: https://doi.org/10.1089/aid.2011.0143

29. Lairmore MD, Jacobson S, Gracia F, De BK, Castillo $\mathrm{L}$, Larreategui M, et al. Isolation of human T-cell lymphotropic virus type 2 from Guaymi Indians in Panama. Proc Natl Acad Sci U S A [Internet]. 1990 Nov [cited 2020 0ct 15]; 87(22):8840-4. Available from: https://dx.doi.org/10.1073\%2Fpnas.87.22.8840

30. Nunes D, Boa-Sorte N, Grassi MFR, Taylor GP, Teixeira MG, Barreto ML, et al. HTLV-1 is predominantly sexually transmitted in Salvador, the city with the highest HTLV-1 prevalence in Brazil. PLoS One [Internet]. 2017 Feb [cited 2020 Oct 15]; 12:e0171303. Available from: https:// doi.org/10.1371/journal.pone.0171303

31. Costa CA, Furtado KCYO, Ferreira LSC, Almeida DS, Linhares AC, Ishak R, et al. Familial Transmission of Human T-cell Lymphotrophic Virus: Silent Dissemination of an Emerging but Neglected Infection. PLoS Negl Trop Dis [Internet]. 2013 Jun [cited 2020 Oct 15]; 7:e2272. Available from: https://doi.org/10.1371/journal.pntd.0002272

32. Satake M, Yamaguchi K, Tadokoro K. Current prevalence of HTLV-1 in Japan as determined by screening of blood donors. J Med Virol [Internet]. 2012 Feb [cited 2020 0ct 15]; 84(2):327-35. Available from: https://doi.org/10.1002/jmv.23181
33. Hananiya HS, Ella EE, Aminu M, Anyanwu NCJ. Prevalence of human T-cell lymphotropic virus and the socio-demographic and risk factors associated with the infection among post-natal clinics women in Zaria, Nigeria. J Immunoassay Immunochem [Internet]. 2019 [cited 2020 0ct 15]; 40(5):485-94. Available from: https://doi.org/10.1080/15321819.2019.1636817

34. Braço ILJ, Sá KSG, Waqasi M, Queiroz MAF, Silva ANR, Cayres-Vallinoto IMV, et al. High prevalence of human T-lymphotropic virus 2 (HTLV-2) infection in villages of the Xikrin tribe (Kayapo), Brazilian Amazon region. BMC Infect Dis [Internet]. 2019 May [cited 2020 0ct 15]; 19(1):459. Available from: https://doi.org/10.1186/s12879-019-4041-0

35. Murphy EL, Figueroa JP, Gibbs WN, Brathwaite A, Holding-Cobham M, Waters D, et al. Sexual transmission of human T-lymphotropic virus type I (HTLV-I). Ann Intern Med [Internet]. 1989 0ct [cited 2020 0ct 15]; 111(7):555-60. Available from: https://doi.org/10.7326/0003-4819-111-7-555

36. La Rosa AM, Zunt JR, Peinado J, Lama JR, Ton TGN, Suarez L, et al. Retroviral infection in Peruvian men who have sex with men. Clin Infect Dis [Internet]. 2009 Jul [cited 2020 0ct 15]; 49(1):112-7. Available from: https://dx.doi.org/10.1086\%2F599609

37. Zunt JR, La Rosa AM, Peinado J, Lama JR, Suarez L, Pun M, et al. Risk factors for HTLV-II infection in Peruvian men who have sex with men. Am J Trop Med Hyg [Internet]. 2006 May [cited 2020 0ct 15]; 74(5):922-5. Available from: https://www.ncbi.nlm. nih.gov/entrez/eutils/elink.fcgi?dbfrom=pubme$\mathrm{d} \&$ retmode $=$ ref\&cmd $=$ prlinks\&id $=16687704$

38. Galvão-Castro B, Loures L, Rodriques LG, Sereno A, Ferreira Júnior OC, Franco LG, et al. Distribution of human T-lymphotropic virus type I among blood donors: a nationwide Brazilian study. Transfusion [Internet]. 1997 Feb [cited 2020 0ct 15]; 37(2):242-3. Available from: https://doi. org/10.1046/j.1537-2995.1997.37297203532.x

39. Ishak R, Ishak MOG, Vallinoto ACR. The challenge of describing the epidemiology of HTLV in the Amazon region of Brazil. Retrovirology [Internet]. 2020 Feb [cited 2020 oct 15]; 17:4. Available from: https://dx.doi.org/10.1186\%2Fs12977-020-0512-Z

40. Einsiedel L, Woodman RJ, Flynn M, Wilson K, Cassar 0 , Gessain A. Human T-lymphotropic virus type 1 infection in an indigenous Australian population: epidemiological insights from a hospital-based cohort study. BMC Public Health [Internet]. 2016 
Aug [cited 2020 0ct 15]; 16:787. Available from: https://doi.org/10.1186/s12889-016-3366-5

41. Paiva AM, Assone T, Haziot MEJ, Smid J, Fonseca LAM, Luiz OC, et al. Risk factors associated with HTLV-1 vertical transmission in Brazil: longer breastfeeding, higher maternal proviral load and previous HTLV-1-infected offspring. Sci Rep [Internet]. 2018 [cited 2020 0ct 15]; 8:7742. Available from: https://doi.org/10.1038/s41598-018-25939-y

42. Brasil. Ministério da Saúde. Portaria GM/MS n. 1376, de 19 de novembro de 1993. Aprova alterações na Portaria no 721/GM, de 09.08.89, que aprova Normas Técnicas para coleta, processamento e transfusão de sangue, componentes e derivados, e dá outras providências [Internet]. Diário Oficial da União, Brasília (DF), 1993 dez 2 [citado 2020 out 15]; Seção I:18405. Disponível em: http:// redsang.ial.sp.gov.br/site/docs_leis/ps/ps29.pdf

43. Hjelle B, Appenzeller 0, Mills R, Appenzeller 0, Jahnke R, Alexander S, et al. Chronic neurodegenerative disease associated with HTLV-II infection. Lancet [Internet].1992 Mar [cited 2020 0ct 15]; 339(8794):645-6. Available from: https://doi. org/10.1016/0140-6736(92)90797-7

44. Zucker-Franklin D, Hooper WC, Evatt BL. Human lymphotropic retroviruses associated with mycosis fungoides: evidence that human T-cell lymphotropic virus type II (HTLV-II) as well as HTLV-I may play a role in the disease. Blood [Internet]. 1992 Sep [cited 2020 0ct 15]; 80(6):1537-45. Available from: https://pubmed.ncbi.nlm.nih.gov/1520878/

45. Maytal J, Horowitz S, Lipper S, Poiesz B, Wang CY, Siegal FP. Progressive nemaline rod myopathy in a woman coinfected with HIV-1 and HTLV-2. Mt Sinai J Med. 1993 May;60(3):242-6.

46. Peters AA, Oger JJ, Coulthart MB, Waters DJ, Cummings HJ, Dekaban GA. An apparent case of human T-cell lymphotropic virus type II (HTLV-II)-associated neurological disease: a clinical, molecular, and phylogenetic characterisation. J Clin Virol [Internet]. 1999 Sep [cited 2020 0ct 15]; 14(1):37-50. Available from: https://doi.org/10.1016/S1386-6532(99)00041-4

47. Araujo A, Hall WW. Human T-Lymphotropic virus type ii and neurological disease. Ann Neurol [Internet]. 2004 Jul [cited 2020 0ct 15]; 56(1):10-9. Available from: https://oi.org/10.1002/ana.20126

48. Rosadas C, Vicente ACP, Zanella L, Cabral-Castro MJ, Peralta JM, Puccioni-Sohler M. Human
T-lymphotropic virus type 2 subtype b in a patient with chronic neurological disorder.J Neurovirol [Internet]. 2014 Dec [cited 2020 0ct 15]; 20(6):636-9. Available from: https://doi.org/10.1007/s13365-014-0280-4

49. Black FL. Tracing prehistoric migrations by the viruses they carry: human T-cell lymphotropic viruses as markers of ethnic relationships. Hum Biol. 1997 Aug;69(4):467-82.

50. Ishak R, Machado LFA, Cayres-Vallinoto I, Guimarães Ishak M0, Vallinoto ACR. Infectious agents as markers of human migration toward the Amazon Region of Brazil. Front Microbiol [Internet]. 2017 Aug [cited 2020 0ct 15]; 8:1663. Available from: https://dx.doi.org/10.3389\%2Ffmicb.2017.01663

51. Katsuya H, Ishitsuka K, Utsunomiya A, Hanada S, Eto T, Moriuchi Y, et al. Treatment and survival among 1594 patients with ATL. Blood [Internet]. 2015 Dec [cited 2020 0ct 15]; 126(24):2570-7. Available from: https://doi.org/10.1182/blood-2015-03-632489

52. Taniguchi H, Imaizumi Y, Takasaki Y, Nakashima $\mathrm{J}$, Kato T, Itonaga $\mathrm{H}$, et al. Clinical features at transformation in adult T-cell leukemia-lymphoma with smoldering and chronic types. Int J Hematol [Internet]. 2019 Apr [cited 2020 Oct 15]; 109(4):402-8. Available from: https:// doi.org/10.1007/s12185-019-02602-4

53. Rodgers-Johnson P, Gajdusek DC, Morgan OS, Zaninovic V, Sarin PS, Graham DS. HTLV-I and HTLV-III antibodies and tropical spastic paraparesis. Lancet (London, England) [Internet]. 1985 0ct [cited 2020 0ct 15]; 2(8466):1247-8. Available from: https://doi.org/10.1016/s0140-6736(85)90778-0

54. Osame M, Usuku K, Izumo S, Ijichi N, Amitani H, Igata A, et al. HTLV-I associated myelopathy, a new clinical entity. Lancet [Internet]. 1986 May [cited 2020 0ct 15]; 1(8488):1031-2. Available from: https://doi.org/10.1016/s0140-6736(86)91298-5

55. Araujo AQ-C. Update on neurological manifestations of HTLV-1 infection. Curr Infect Dis Rep [Internet]. $2015 \mathrm{Feb}$ [cited 2020 0ct 15]; 17(2):459. Available from: https://doi.org/10.1007/s11908-014-0459-0

56. Bangham CRM, Araujo A, Yamano Y, Taylor GP. HTLV-1-associated myelopathy/tropical spastic paraparesis. Nat Rev Dis Primers [Internet]. 2015 Jun [cited 2020 0ct 15]; 1:15012. Available from: https://doi.org/10.1038/nrdp.2015.12

57. Nozuma S, Jacobson S. Neuroimmunology of human T-Lymphotropic virus type 1-associated myelopathy/ 
tropical spastic paraparesis. Front Microbiol [Internet]. 2019 Apr [cited 2020 0ct 15]; 10:885. Available from: https://dx.doi.org/10.3389\%2Ffmicb.2019.00885

58. Chew R, Henderson T, Aujla J, Whist E, Einsiedel L. Turning a blind eye: HTLV-1-associated uveitis in Indigenous adults from Central Australia. Int Ophthalmol [Internet]. 2018 0ct [cited 2020 Oct 15]; 38(5):2159-62. Available from: https://doi.org/10.1007/s10792-017-0659-3

59. Nakao K, Abematsu N, Sakamoto T. Systemic diseases in patients with HTLV-1-associated uveitis. Br J 0phthalmol [Internet]. 2018 Mar [cited 2020 Oct 15]; 102(3):373-6. Available from: https:// doi.org/10.1136/bjophthalmol-2017-310658

60. Kamoi K, Okayama A, Izumo S, Hamaguchi I, Uchimaru K, Tojo A, et al. Tackling HTLV-1 infection in ophthalmology: a nationwide survey of ophthalmic care in an endemic country, Japan. Br J 0phthalmol [Internet]. 2020 Mar [cited 2020 0ct 15]. Available from: https:// doi.org/10.1136/bjophthalmol-2019-315675

61. Schierhout G, McGregor S, Gessain A, Einsiedel L, Martinello M, Kaldor J. Association between HTLV-1 infection and adverse health outcomes: a systematic review and meta-analysis of epidemiological studies. Lancet Infect Dis [Internet]. 2019 Jan [cited 2020 0ct 15]; 20(1):133-43. Available from: https://doi.org/10.1016/s1473-3099(19)30402-5

62. Bimbi C, Brzezinski P, Sokolowska-Wojdylo M. Crusted (Norwegian) scabies as a strong marker of adult T-cell leukemia/lymphoma in HTLV-1 infection. Clin Case Reports [Internet]. 2019 Mar [cited 2020 0ct 15]; 7(3):474-6. Available from: https://dx.doi.org/10.1002\%2Fccr3.1983

63. Magno Falcão LF, Falcão ASC, Medeiros Sousa RC, Vieira WB, Oliveira RTM, Normando VMF, et al. CT Chest and pulmonary functional changes in patients with HTLV-associated myelopathy in the Eastern Brazilian Amazon. PLoS One [Internet]. 2017 Nov [cited 2020 0ct 15]; 12(11):e0186055. Available from: https://doi.org/10.1371/journal.pone.0186055

64. Dias ARN, Falcão LFM, Falcão ASC, Normando VMF, Quaresma JAS. Human T lymphotropic virus and pulmonary diseases. Front Microbiol [Internet]. 2018 Aug [cited 2020 0ct 15]; 9:1879. Available from: https://dx.doi.org/10.3389\%2Ffmicb.2018.01879
65. Kako S, Joshita S, Matsuo A, Kawaguchi K, Umemura T, Tanaka E. A case of adult T-Cell leukemia/ lymphoma complicated with bilateral chylothorax. Case Rep Oncol Med [Internet]. 2019 Feb [cited 2020 0ct 15]; 2019:8357893. Available from: https://doi.org/10.1155/2019/8357893

66. Nishioka K, Maruyama I, Sato K, Kitajima I, Nakajima Y, Osame M. Chronic inflammatory arthropathy associated with HTLV-I. Lancet [Internet]. 1989 Feb [cited 2020 0ct 15]; 1(8635):441. Available from: https://doi.org/10.1016/s0140-6736(89)90038-x

67. Sato K, Maruyama I, Maruyama Y, Kitajima I, Nakajima Y, Higaki M, et al. Arthritis in patients infected with human T lymphotropic virus type I. Clinical and immunopathologic features. Arthritis Rheum [Internet]. 1991 Jun [cited 2020 0ct 15]; 34(6):714-21. Available from: https://doi.org/10.1002/art.1780340612

68. Dennis G, Chitkara P. A case of human T lymphotropic virus type I-associated synovial swelling. Nat Clin Pract Rheumatol [Internet]. 2007 Nov [cited 2020 0ct 15]; 3:675-80. Available from: https://doi.org/10.1038/ncprheum0648

69. Kawai H, Inui T, Kashiwagi S, Tsuchihashi T, Masuda K, Kondo A, et al. HTLV-I infection in patients with autoimmune thyroiditis (Hashimoto's thyroiditis). J Med Virol [Internet]. 1992 Oct [cited 2020 0ct 15]; 38(2):138-41. Available from: https://doi.org/10.1002/jmv.1890380212

70. Matsuda T, Tomita M, Uchihara J-N, Okudaira T, Ohshiro K, Tomoyose T, et al. Human T cell leukemia virus type I-infected patients with Hashimoto's thyroiditis and Graves' disease. $\mathrm{J}$ Clin Endocrinol Metab [Internet]. 2005 0ct [cited 2020 0ct 15]; 90(10):5704-10. Available from: https://doi.org/10.1210/jc.2005-0679

71. Abolbashari S, Darroudi S, Tayefi M, Khashyarmaneh Z, Zamani P, Haghighi HM, et al. Association between serum zinc and copper levels and antioxidant defense in subjects infected with human T-lymphotropic virus type 1. J Blood Med [Internet]. 2018 Dec [cited 2020 0ct 15]; 10:29-35. Available from: https://doi.org/10.2147/jbm.s184913

72. Mohammadi FS, Mosavat A, Shabestari M, Shabestari M, Ghezeldasht SA, Shabestari M, et al. HTLV-1-host interactions facilitate the manifestations of cardiovascular disease. Microb Pathog [Internet]. 2019 Sep [cited 2020 0ct 15]; 134:103578. Available from: https://doi.org/10.1016/j.micpath.2019.103578 
73. Oliveira TSS, Andrade RCP, Santos DN, Orrico KF, Abraão Neto J, Oliveira CJV, et al. Prevalence of Bowel Symptoms in Patients Infected with Human T-Lymphotropic type 1 Virus. Rev Soc Bras Med Trop [Internet]. 2019 Nov [cited 2020 Oct 15]; 52:e20180486. Available from: http:// dx.doi.org/10.1590/0037-8682-0486-2018

74. Silva MT, Coutinho F, Leite AC, Harab RC, Araújo A, Andrada-Serpa MJ. Isolated bladder dysfunction in human T lymphotropic virus type 1 infection. Clin Infect Dis [Internet]. 2009 Feb [cited 2020 0ct 15]; 48(3):e34-6. Available from: https://doi.org/10.1086/595855

75. Nayar S, Pawar B, Einsiedel L, Fernandes D, George P, Thomas S, et al. Isolated neurogenic bladder associated with human T-Lymphotropic virus type 1 infection in a renal transplant patient from central Australia: a case report. Transplant Proc [Internet]. $2018 \mathrm{Dec}$ [cited 2020 0ct 15]; 50(10):3940-2. Available from: https://doi.org/10.1016/j.transproceed.2018.08.031

76. Tanajura D, Castro N, Oliveira P, Abraão Neto, Muniz A, Carvalho NB, et al. Neurological manifestations in human T-cell lymphotropic virus type 1 (HTLV-1)-infected individuals without HTLV-1-associated myelopathy/tropical spastic paraparesis: a longitudinal cohort study. Clin Infect Dis [Internet]. 2015 Jul [cited 2020 0ct 15]; 61(1):49-56. Available from: https://doi.org/10.1093/cid/civ229

77. Haziot ME, Gascon MR, Assone T, Fonseca LAM, Luiz OC, Smid J, et al. Detection of clinical and neurological signs in apparently asymptomatic HTLV-1 infected carriers: Association with high proviral load. PLoS Negl Trop Dis [Internet]. 2019 May [cited 2020 0ct 15]; 13:e0006967. Available from: https://doi.org/10.1371/journal.pntd.0006967

78. Yamano Y, Nagai M, Brennan M, Mora CA, Soldan SS, Tomaru U, et al. Correlation of human T-cell lymphotropic virus type 1 (HTLV-1) mRNA with proviral DNA load, virus-specific CD8+ T cells, and disease severity in HTLV-1-associated myelopathy (HAM/TSP). Blood [Internet]. 2002 Jan [cited 202 0ct 15]; 99(1):88-94. Available from: https://doi.org/10.1182/blood.v99.1.88

79. Montanheiro PA, Oliveira ACP, Posada-Vergara MP, Milagres AC, Tauil C, et al. Human T-cell lymphotropic virus type I (HTLV-I) proviral DNA viral load among asymptomatic patients and patients with HTLV-I-associated myelopathy/tropical spastic paraparesis. Brazilian J Med Biol Res [Internet]. 2005 Nov [cited 2020 0ct 15]; 38(11):1643-7. Available from: http:// dx.doi.org/10.1590/S0100-879X2005001100011
80. Champs APS, Passos VMA, Barreto SM, Vaz LS, Ribas JGR. HTLV-1 associated myelopathy: clinical and epidemiological profile in a 10 -year case series study. Rev Soc Bras Med Trop [Internet]. 2010 [cited 2020 0ct 15]; 43(6):668-72. Available from: http:// dx.doi.org/10.1590/S0037-86822010000600013

81. Okajima R, Casseb J, Sanches JA. Co-presentation of human T-cell lymphotropic virus type 1 (HTLV-1)-associated myelopathy/tropical spastic paraparesis and adult-onset infective dermatitis associated with HTLV-1 infection. Int J Dermatol [Internet]. 2013 Jan [cited 2020 0ct 15]; 52(1):63-8. Available from: https://doi.org/10.1111/j.1365-4632.2012.05606.x

82. Okajima R, Oliveira ACP, Smid J, Casseb J, Sanches JA. High prevalence of skin disorders among HTLV-1 infected individuals independent of clinical status. PLoS Negl Trop Dis [Internet]. 2013 Nov [cited 2020 0ct 15]; 7(11):e2546. Available from: https:// dx.doi.org/10.1371\%2Fjournal.pntd.0002546

83. Araujo AQC, Wedemann D. HTLV-1 Associated neurological complex. What is hidden below the water? AIDS Rev [Internet]. 2019 [cited 2020 Oct 15]; 21(4):211-7. Available from: https:// doi.org/10.24875/aidsrev.19000108

84. Matsuzaki T, Nakagawa M, Nagai M, Usuku K, Arimura $\mathrm{K}$, Kubota H, et al. HTLV-I proviral load correlates with progression of motor disability in HAM/TSP: analysis of $239 \mathrm{HAM} / \mathrm{TSP}$ patients including 64 patients followed up for 10 years. J Neurovirol [Internet]. 2001 Jun [cited 2020 0ct 15]; 7(3):228-34. Available from: https://doi.org/10.1080/13550280152403272

85. Rosadas C, Puccioni-Sohler M. Relevance of retrovirus quantification in cerebrospinal fluid for neurologic diagnosis. J Biomed Sci [Internet]. 2015 Aug [cited 2020 Oct 15]; 22(1):66. Available from: https://doi.org/10.1186/s12929-015-0170-y

86. Hayashi D, Kubota R, Takenouchi N, Nakamura T, Umehara F, Arimura K, et al. Accumulation of human T-lymphotropic virus type I (HTLV-I)-infected cells in the cerebrospinal fluid during the exacerbation of HTLV-I-associated myelopathy. J Neurovirol [Internet]. 2008 0ct [cited 2020 0ct 15]; 14(5):459-63. Available from: https://doi.org/10.1080/13550280802178538

87. Lezin A, Olindo S, Oliere S, Varrin-Doyer M, Martin R, Cabre P, et al. Human T lymphotropic virus type I (HTLV-I) proviral load in cerebrospinal fluid: a new criterion for the diagnosis of HTLV-I-associated myelopathy/tropical spastic paraparesis? J Infect Dis [Internet]. 2005 Jun 
[cited 2020 0ct 15]; 191(11):1830-4. Available from: https://doi.org/10.1086/429962

88. Starling ALB, Coelho-dos-Reis JGA, Peruhype-Magalhães V, Pascoal-Xavier MA, Gonçalves DU, Béia SR, et al. Immunological signature of the different clinical stages of the HTLV-1 infection: establishing serum biomarkers for HTLV-1-associated disease morbidity. Biomarkers [Internet]. 2015 [cited 2020 Oct 15]; 20(6-7):502-12. Available from: https:// doi.org/10.3109/1354750x.2015.1094141

89. Yamauchi J, Araya N, Yagishita N, Sato T, Yamano Y. An update on human T-cell leukemia virus type I (HTLV-1)-associated myelopathy/tropical spastic paraparesis (HAM/TSP) focusing on clinical and laboratory biomarkers. Pharmacol Ther [Internet]. 2020 Aug [cited 2020 0ct 15]; 107669. Available from: https://doi.org/10.1016/j.pharmthera.2020.107669

90. Apoliano CF, Assone T, Maciel da Silva BC, Corral MA, Oliveira ACP, Fonseca LAM, et al. Interferon- $\gamma$ secretion enzyme-linked immunospot assay determined among human T cell lymphotropic virus type 1-infected subjects: a potential laboratory marker for early HTLV-1-associated myelopathy/tropical spastic paraparesis diagnosis. AIDS Res Hum Retroviruses [Internet]. 2020 Jan [cited 2020 0ct 15]; 36(1):6-7. Available from: https://doi.org/10.1089/aid.2018.0290

91. Tajima K, Cartier L. Epidemiological features of HTLV-I and adult T cell leukemia. Intervirology [Internet]. 1995 [cited 2020 0ct 15]; 38(3-4):238-46. Available from: https://doi.org/10.1159/000150438

92. Kondo T, Kono H, Miyamoto N, Yoshida R, Toki H, Matsumoto I, et al. Age- and sex-specific cumulative rate and risk of ATLL for HTLV-I carriers. Int J cancer [Internet]. 1989 Jun [cited 2020 0ct 15]; 43(6):1061-4. Available from: https://doi.org/10.1002/ijc.2910430618

93. Nosaka K, Iwanaga M, Imaizumi Y, Ishitsuka K, Ishizawa K, Ishida Y, et al. Epidemiological and clinical features of adult T-cell leukemia-lymphoma in Japan, 2010-2011: a nationwide survey. Cancer Sci [Internet]. 2017 Dec [cited 2020 0ct 15]; 108(12):2478-86. Available from: https://doi.org/10.1111/cas.13398

94. Iwanaga M, Watanabe T, Utsunomiya A, Okayama A, Uchimaru K, Koh KR, et al. Human T-cell leukemia virus type I (HTLV-1) proviral load and disease progression in asymptomatic HTLV-1 carriers: a nationwide prospective study in Japan. Blood [Internet]. 2010 Aug [cited 2020 0ct 15]; 116(8):1211-9. Available from: https://doi.org/10.1182/blood-2009-12-257410
95. Phillips AA, Shapira I, Willim RD, Sanmugarajah J, Solomon WB, Horwitz SM, et al. A critical analysis of prognostic factors in North American patients with human T-cell lymphotropic virus type-1-associated adult T-cell leukemia/lymphoma: a multicenter clinicopathologic experience and new prognostic score. Cancer [Internet]. $2010 \mathrm{Jul}$ [cited 2020 0ct 15]; 116(14):3438-46. Available from: https://doi.org/10.1002/cncr.25147

96. Rosadas C, Puccioni-Sohler M, Oliveira ACP, Casseb J, Sousa M, Taylor GP. Adult T-cell leukaemia/ lymphoma in Brazil: a rare disease or rarely diagnosed? Br J Haematol [Internet]. $2020 \mathrm{Feb}$ [cited 2020 0ct 15]; 188(4):e46-9. Available from: https://doi.org/10.1111/bjh.16318

97. van Tienen C, Visser O, Lugtenburg P, Taylor G, Cook L. Overrepresentation of patients from HTLV-1 endemic countries among T cell Non-Hodgkin lymphomas in the Netherlands: an indication of under-diagnosis of Adult T cell leukaemia/lymphoma. Br J Haematol [Internet]. 2018 Feb [cited 2020 0ct 15]; 184(4):6889. Available from: https://doi.org/10.1111/bjh.15160

98. Lymphoma Study Group. Major prognostic factors of patients with adult T-cell leukemia-lymphoma: a cooperative study. Leuk Res [Internet]. 1991 [cited 2020 0ct 15]; 15(2-3):81-90. Available from: https://doi.org/10.1016/0145-2126(91)90087-A

99. Tsukasaki K, Hermine 0, Bazarbachi A, Ratner L, Ramos JC, Harrington Jr W, et al. Definition, prognostic factors, treatment, and response criteria of adult T-cell leukemia-lymphoma: a proposal from an international consensus meeting. J Clin Oncol [Internet]. 2009 Jan [cited 2020 0ct 15]; 27(3):453-9. Available from: https://doi.org/10.1200/jco.2008.18.2428

100. Shimoyama M. Diagnostic criteria and classification of clinical subtypes of adult T-cell leukaemia-lymphoma. A report from the Lymphoma Study Group (1984-87). Br J Haematol [Internet]. 1991 Nov [cited 2020 0ct 15]; 79(3):428-37. Available from: https:// doi.org/10.1111/j.1365-2141.1991.tb08051.x

101. Yared JA, Kimball AS. Optimizing management of patients with adult $\mathrm{T}$ cell leukemia-lymphoma. Cancers (Basel) [Internet]. 2015 Dec [cited 2020 Oct 15]; 7(4):2318-29. Available from: https:// dx.doi.org/10.3390\%2Fcancers 7040893

102. Brites C, Weyll M, Pedroso C, Badaró R. Severe and Norwegian scabies are strongly associated with retroviral (HIV-1/HTLV-1) infection in Bahia, Brazil. AIDS [Internet]. 2002 Jun [cited 2020 
Oct 15]; 16(9):1292-3. Available from: https:// doi.org/10.1097/00002030-200206140-00015

103. Dantas L, Netto E, Glesby MJ, Carvalho EM, Machado P. Dermatological manifestations of individuals infected with human T cell lymphotropic virus type I (HTLV-I). Int J Dermatol [Internet]. 2014 Sep [cited 2020 0ct 15]; 53(9):1098-102. Available from: https://doi.org/10.1111/ijd.12170

104. LaGrenade L, Hanchard B, Fletcher V, Cranston $\mathrm{B}$, Blattner W. Infective dermatitis of Jamaican children: a marker for HTLV-I infection. Lancet (London, England) [Internet]. 1990 Dec [cited 2020 0ct 15]; 336(8727):1345-7. Available from: https://doi.org/10.1016/0140-6736(90)92896-p

105. Bittencourt AL, Primo J, Oliveira MFP. Manifestations of the human T-cell lymphotropic virus type I infection in childhood and adolescence. J Pediatr (Rio J) [Internet]. 2006 [cited 2020 0ct 15]; 82(6):411-20. Available from: http://dx.doi.org/10.2223/JPED.1573

106. Oliveira MFSP, Fatal PL, Primo JRL, Silva JLS, Batista ES, Ferré L, et al. Infective dermatitis associated with human T-cell lymphotropic virus type 1: evaluation of 42 cases observed in Bahia, Brazil. Clin Infect Dis [Internet]. 2012 Jun [cited 2020 oct 15]; 54(12):17149. Available from: https://doi.org/10.1093/cid/cis273

107. Bittencourt AL, Oliveira MFP. Cutaneous manifestations associated with HTLV-1 infection. Int J Dermatol [Internet]. 2010 0ct [cited 2020 0ct 15]; 49(10):1099-110. Available from: https:// doi.org/10.1111/j.1365-4632.2010.04568.x

108. Ohba N, Matsumoto M, Sameshima M, Kabayama Y, Nakao K, Unoki K, et al. Ocular manifestations in patients infected with human T-lymphotropic virus type I. Jpn J Ophthalmol. 1989;33(1):1-12.

109. Mochizuki M, Tajima K, Watanabe T, Yamaguchi K. Human T lymphotropic virus type 1 uveitis. Br J 0phthalmol [Internet]. 1994 Feb [cited 2020 0ct 15]; 78(2):149-54. Available from: https://dx.doi.org/10.1136\%2Fbjo.78.2.149

110. Brites C, Sampalo J, Oliveira A. HIV/human T-cell lymphotropic virus coinfection revisited: impact on AIDS progression. AIDS Rev [Internet]. 2009 Jan-Mar [cited 2020 0ct 15]; 11(1):8-16. Available from: https://pubmed.ncbi.nlm.nih.gov/19290030/

111. Pedroso C, Netto EM, Weyll N, Brites C. Coinfection by HIV-1 and human lymphotropic virus type 1 in Brazilian children is strongly associated with a shorter survival time. J Acquir Immune
Defic Syndr [Internet]. 2011 Aug [cited 2020 0ct 15]; 57 Suppl 3:S208-11. Available from: https:// doi.org/10.1097/qai.0b013e31821e9baf

112. Brites C, Miranda F, Luz E, Netto EM. Early and successful combination antiretroviral therapy normalizes survival time in patients coinfected with human immunodeficiency virus and human T-cell lymphotrophic virus type 1. Clin Infect Dis [Internet]. 2020 Jun [cited 2020 0ct 15]; 71(1):196-200. Available from: https://doi.org/10.1093/cid/ciz756

113. Boschi-Pinto C, Stuver S, Okayama A, Trichopoulod D, Orav EJ, Tsubouchi H, et al. A followu-p study of morbidity and mortality associated with hepatitis $\mathrm{C}$ virus infection and its interaction with human $\mathrm{T}$ lymphotropic virus type I in Miyazaki, Japan. J Infect Dis [Internet]. 2000 Jan [cited 2020 0ct 15]; 181(1):3541. Available from: https://doi.org/10.1086/315177

114. Brites C, Abrahão M, Bozza P, Netto EM, Lyra A, Bahia F. Infection by HTLV-1 Is associated with high levels of proinflammatory cytokines in HIV-HCV-coinfected patients. J Acquir Immune Defic Syndr [Internet]. 2018 Feb [cited 2020 0ct 15]; 77(2):230-4. Available from: https://doi.org/10.1097/qai.0000000000001576

115. Bahia F, Novais V, Evans J, Marchand CL, Netto E, Page $\mathrm{K}$, et al. The impact of human T-cell lymphotropic virus i infection on clinical and immunologic outcomes in patients coinfected with HIV and hepatitis $\mathrm{C}$ virus. J Acquir Immune Defic Syndr [Internet]. 2011 Aug [cited 2020 0ct 15]; 57(3):S202-7. Available from: https://dx.doi.org/10.1097\%2FQAI.0b013e31821e9a1e

116. Marchand CL, Bahia F, Page K, Brites C. Hepatitis $\mathrm{C}$ virus infection and spontaneous clearance in HTLV-1 and HIV co-infected patients in Salvador, Bahia, Brazil. Braz J Infect Dis [Internet]. 2015 [cited 2020 0ct 15]; 19(5):486-91. Available from: http://dx.doi.org/10.1016/j.bjid.2015.06.007

117. Gillet NA, Cook L, Laydon DJ, Hlela C, Verdonck $\mathrm{K}$, Alvarez C, et al. Strongyloidiasis and infective dermatitis alter human T lymphotropic virus-1 clonality in vivo. PLoS Pathog [Internet]. $2013 \mathrm{Apr}$ [cited 2020 0ct 15]; 9(4):e1003263. Available from: https://dx.doi.org/10.1371\%2Fjournal.ppat.1003263

118. Nakada K, Yamaguchi K, Furugen S, Nakasone $\mathrm{K}$, Oshiro Y, Kohakura M, et al. Monoclonal integration of HTLV-I proviral DNA in patients with strongyloidiasis. Int J Cancer [Internet]. 1987 Aug [cited 2020 0ct 15]; 40(2):145-8. Available from: https://doi.org/10.1002/ijc.2910400203 
119. Newton RC, Limpuangthip P, Greenberg S, Gam A, Neva FA. Strongyloides stercoralis hyperinfection in a carrier of HTLV-I virus with evidence of selective immunosuppression. Am J Med [Internet]. $1992 \mathrm{Feb}$ [cited 2020 0ct 15]; 92(2):202-8. Available from: https://doi.org/10.1016/0002-9343(92)90113-p

120. Terashima A, Alvarez H, Tello R, Infante R, Freedman D0, Gotuzzo E. Treatment failure in intestinal strongyloidiasis: an indicator of HTLV-I infection. Int J Infect Dis [Internet]. 2002 Mar [cited 2020 0ct 15]; 6(1):28-30. Available from: https://doi.org/10.1016/s1201-9712(02)90132-3

121. Gotuzzo E, Moody J, Verdonck K, Cabada MM, González E, van Dooren S, et al. Frequent HTLV1 infection in the offspring of Peruvian women with HTLV-1 - associated myelopathy / tropical spastic paraparesis or strongyloidiasis. Rev Panam Salud Publica [Internet]. 2007 0ct [cited 2020 Oct 15]; 22(4):223-30. Available from: https:// doi.org/10.1590/s1020-49892007000900001

122. Porto MAF, Muniz A, Oliveira Júnior J, Carvalho EM. Implicações clinicas e imunológicas da associação entre o HTLV-1 e a estrongiloidíase. Rev Soc Bras Med Trop [Internet]. 2002 [citado 2020 out 15]; 35(6):641-9. Disponível em: https:// doi.org/10.1590/S0037-86822002000600016

123. Sato Y, Shiroma Y. Concurrent infections with Strongyloides and T-cell leukemia virus and their possible effect on immune responses of host. Clin Immunol Immunopathol [Internet]. 1989 Aug [cited 2020 0ct 15]; 52(2):214-24. Available from: https://doi.org/10.1016/0090-1229(89)90173-6

124. Salles F, Bacellar A, Amorim M, Orge G, Sundberg M, Lima M, et al. Treatment of strongyloidiasis in HTLV-1 and Strongyloides stercoralis coinfected patients is associated with increased tnf $\alpha$ and decreased soluble IL2 receptor levels. Trans R Soc Trop Med Hyg [Internet]. $2013 \mathrm{Aug}$ [cited 2020 0ct 15]; 107(8):526-9. Available from: https://doi.org/10.1093/trstmh/trt052

125. Gabet A-S, Mortreux F, Talarmin A, Plumelle Y, Leclercq I, Leroy A, et al. High circulating proviral load with oligoclonal expansion of HTLV-1 bearing T cells in HTLV-1 carriers with strongyloidiasis. Oncogene [Internet]. 2000 0ct [cited 2020 0ct 15]; 19(43):4954-60. Available from: https://doi.org/10.1038/sj.onc.1203870

126. Plumelle Y, Gonin C, Edouard A, Bucher BJ, Thomas L, Brebion A, et al. Effect of Strongyloides stercoralis infection and eosinophilia on age at onset and prognosis of adult T-cell leukemia. Am J Clin Pathol [Internet]. 1997 Jan [cited 2020 0ct 15]; 107(1):81-7. Available from: https://doi.org/10.1093/ajcp/107.1.81

127. Schierhout G, McGregor S, Gessain A, Einsiedel L, Martinello M, Kaldor J. Association between HTLV-1 infection and adverse health outcomes: a systematic review and meta-analysis of epidemiological studies. Lancet Infect Dis [Internet]. 2019 Apr [cited 2020 0ct 15]; 20(4):407-8. Available from: https://doi.org/10.1016/S1473-3099(20)30133-X

128. Marinho J, Galvao-Castro B, Rodrigues LC, Barreto ML. Increased risk of tuberculosis with human T-lymphotropic virus-1 infection a case-control study. J Acquir Immune Defic Syndr [Internet]. 2005 [cited 2020 0ct 15]; 40(5):625-8. Available from: https://www.arca.fiocruz.br/handle/icict/8131

129. Norrgren HR, Bamba S, Larsen O, Silva Z, Aaby P, Koivula T, et al. Increased prevalence of HTLV-1 in patients with pulmonary tuberculosis coinfected with HIV, but not in HIV-negative patients with tuberculosis. J Acquir Immune Defic Syndr [Internet]. 2008 Aug [cited 2020 0ct 15]; 48(5):607-10. Available from: https://doi.org/10.1097/qai.0b013e31817efb83

130. Moreira ED, Ribeiro TT, Swanson P, Sampoio Filho C, Melo A, Brites C, et al. Seroepidemiology of human T-cell lymphotropic virus type I/II in northeastern Brazil. J Acquir Immune Defic Syndr. 1993 Aug;6(8):959-63.

131. Hanada S, Uematsu T, Iwahashi M, Nomura K, Utsunomiya A, Kodama M, et al. The prevalence of human T-cell leukemia virus type I infection in patients with hematologic and nonhematologic diseases in an adult T-cell leukemia-endemic area of Japan. Cancer [Internet]. 1989 Sep [cited 2020 Oct 15]; 64(6):1290-5. Available from: https:// doi.org/10.1002/1097-0142(19890915)64:6\%3C1290::aid-cncr2820640620\%3E3.0.co;2-Z

132. Verdonck K, Gonzalez E, Schrooten W, Vanham G, Gotuzzo E. HTLV-1 infection is associated with a history of active tuberculosis among family members of HTLV-1-infected patients in Peru. Epidemiol Infect [Internet]. $2008 \mathrm{Aug}$ [cited 2020 Oct 15]; 136(8):1076-83. Available from: https:// dx.doi.org/10.1017\%2FS0950268807009521

133. Brasil. Ministério da Saúde. Portaria n. 2.600, de 21 de outubro de 2009. Aprova o Regulamento Técnico do Sistema Nacional de Transplantes [Internet]. Diário Oficial da União, Brasília (DF), 
2009 out 30 [citado 2020 jun 14]; Seção I:77. Disponível em: http:/bvsms.saude.gov.br/bvs/ saudelegis/gm/2009/prt2600_21_10_2009.html

134. Brasil. Ministério da Saúde. Portaria n. 23, de 31 de maio de 2016. Torna pública a decisão de incorporar os procedimentos laboratoriais por técnicas de Western Blot e PCR em tempo real no diagnóstico de leucemia/linfoma de células $\mathrm{T}$ do adulto associado ao HTLV-1, no âmbito do Sistema Único de Saúde - SUS [Internet]. Diário Oficial da União, Brasília (DF), 2016 jun 6 [citado 2020 jun 14]; Seção I:45. Disponível em: http://bvsms.saude.gov.br/bvs/saudelegis/sctie/2016/ prt0023_31_05_2016.html\%09\%09\%09\%09\%09\%09

135. Itabashi K, Miyazawa T, Sekizawa A, Tokita A, Saito $\mathrm{S}$, Moriuchi $\mathrm{H}$, et al. A nationwide antenatal human T-cell leukemia virus type-1 antibody screening in Japan. Front Microbiol [Internet]. 2020 Apr [cited 2020 0ct 15]; 11:595. Available from: https://dx.doi.org/10.3389\%2ffmicb.2020.00595

136. Cassar 0, Gessain A. Serological and molecular methods to study epidemiological aspects of human T-cell lymphotropic virus type 1 infection. Methods Mol Biol [Internet]. 2017 [cited 2020 0ct 15]; 1582:3-24. Available from: https:// doi.org/10.1007/978-1-4939-6872-5_1

137. Puccioni-Sohler M, Grassi MFR, Galvão-Castro B, Caterino A, Proietti ABFC, Vicente ACP, et al. Increasing awareness of human T-lymphotropic virus type-1 infection: a serious, invisible, and neglected health problem in Brazil. Rev Soc Bras Med Trop [Internet]. 2019 Oct [cited 2020 Oct 15]; 52:e20190343. Available from: http://dx.doi.org/10.1590/0037-8682-0343-2019

138. Silva Brito V, Santos FLN, Gonçalves NLS, Araújo THA, Nascimento DSV, Pereira FM, et al. Performance of commercially available serological screening tests for human T-cell lymphotropic virus infection in Brazil. J Clin Microbiol [Internet]. 2018 Nov [cited 2020 0ct 15]; 56(12):e00961. Available from: https://doi.org/10.1128/jcm.00961-18

139. Cánepa C, Salido J, Ruggieri M, Fraile S, Pataccini G, Berinii C, et al. Low Proviral load is associated with indeterminate western blot patterns in human T-cell lymphotropic virus type 1 infected individuals: could punctual mutations be related? Viruses [Internet]. 2015 Nov [cited 2020 0ct 15]; 7(11):5643-58. Available from: https://dx.doi.org/10.3390\%2Fv7112897

140. Tebourski F, Slim A, Elgaaied A. The significance of combining World Health Organization and Center for Disease Control criteria to resolve indeterminate human immunodeficiency virus type-1 Western blot results. Diagn Microbiol Infect Dis [Internet]. 2004 Jan [cited 2020 0ct 15]; 48(1):59-61. Available from: https://doi.org/10.1016/j.diagmicrobio.2003.08.004

141. Ishak R, Vallinoto ACR, Azevedo VN, Vicente ACP, Hall WW, Ishak MOG. Molecular evidence for infection by HTLV-2 among individuals with negative serological screening tests for HTLV antibodies. Epidemiol Infect [Internet]. 2007 May [cited 2020 0ct 15]; 135(4):604-9. Available from: https://doi.org/10.1017/s0950268806006984

142. Kuramitsu M, Sekizuka T, Yamochi T, Firouzi S, Sato T, Umeki K, et al. Proviral features of human T cell leukemia virus type 1 in carriers with indeterminate western blot analysis results. J Clin Microbiol [Internet]. 2017 Sep [cited 2020 0ct 15]; 55(9):2838-49. Available from: https://doi.org/10.1128/jcm.00659-17

143. Araujo AC, Casseb JS, Neitzert E, Souza ML, Mammano F, Mistro AD, et al. HTLV-I and HTLV-II infections among HIV-1 seropositive patients in Sao Paulo, Brazil. Eur J Epidemiol [Internet]. 1994 Apr [cited 2020 0ct 15]; 10(2):165-71. Available from: https://doi.org/10.1007/bf01730366

144. Campos KR, Gonçalves MG, Costa NA, Caterino-de-Araujo A. Comparative performances of serologic and molecular assays for detecting human $\mathrm{T}$ lymphotropic virus type 1 and type 2 (HTLV- 1 and HTLV-2) in patients infected with human immunodeficiency virus type 1 (HIV-1). Brazilian J Infect Dis [Internet]. 2017 [cited 2020 0ct 15]; 21(3):297-305. Available from: http://dx.doi.org/10.1016/j.bjid.2017.02.005

145. Jacob F, Santos-Fortuna E, Azevedo RS, Caterino-de-Araujo A. Serological patterns and temporal trends of HTLV- $1 / 2$ infection in high-risk populations attending Public Health Units in São Paulo, Brazil. J Clin Virol [Internet]. 2008 Jun [cited 2020 0ct 15]; 42(2):149-55. Available from: https://doi.org/10.1016/j.jcv.2008.01.017

146. Morimoto HK, Morimoto AA, Reiche EMV, Ueda LT, Matsuo $\mathrm{T}$, Reiche FV, et al. Difficulties in the diagnosis of HTLV-2 infection in HIV/AIDS patients from Brazil: comparative performances of serologic and molecular assays, and detection of HTLV-2b subtype. Rev Inst Med Trop São Paulo [Internet]. 2007 Jul-Aug [cited 2020 0ct 15]; 49(4):225-30. Available from: http:// dx.doi.org/10.1590/S0036-46652007000400006

147. Mangano AM, Remesar M, del Pozo A, Sen L. Human T lymphotropic virus types I and II proviral sequences in Argentinian blood donors with 
indeterminate Western blot patterns. J Med Virol [Internet]. 2004 0ct [cited 0ct 15]; 74(2):323-7. Available from: https://doi.org/10.1002/jmv.20172

148. Martins ML, Santos ACS, Namen-Lopes MS, Barbosa-Stancioli EF, Utsch DG, Carneiro-Proietti ABF. Long-term serological follow-up of blood donors with an HTLV-Indeterminate Western Blot: Antibody Profile of Seroconverters and Individuals With False Reactions. J Med Virol [Internet]. 2010 Oct [cited 2020 0ct 15]; 82(10):1746-53. Available from: https://doi.org/10.1002/jmv.21881

149. Abrams A, Akahata Y, Jacobson S. The prevalence and significance of HTLV-I/II seroindeterminate western blot patterns. Viruses [Internet]. 2011 Aug [cited 2020 0ct 15]; 3(8):1320-31. Available from: https://dx.doi.org/10.3390\%2Fv3081320

150. Campos KR, Santos FLN, Silva Brito V, Gonçalves NLS, Araújo THA, Galvão-Castro B, et al. Line immunoassay for confirmation and discrimination of human T-cell lymphotropic virus infections in inconclusive western blot serum samples from Brazil. J Clin Microbiol [Internet]. 2019 Dec [cited 2020 0ct 15]; 58(1):e01384-19. Available from: https://doi.org/10.1128/jcm.01384-19

151. Umeki K, Umekita K, Hashikura Y, Yamamoto I, Kubo $\mathrm{K}$, Nagatomo Y, et al. Evaluation of line immunoassay to detect HTLV-1 infection in an endemic area, southwestern Japan; comparison with polymerase chain reaction and western blot. Clin Lab [Internet]. 2017 Feb [cited 2020 0ct 15]; 63(2):227-33. Available from: https://doi.org/10.7754/clin.lab.2016.160501

152. Okuma K, Kuramitsu M, Niwa T, Taniguchi T, Masaki Y, Ueda G, et al. Establishment of a novel diagnostic test algorithm for human T-cell leukemia virus type 1 infection with line immunoassay replacement of western blotting: a collaborative study for performance evaluation of diagnostic assays in Japan. Retrovirology [Internet]. 2020 Aug [cited 2020 0ct 15]; 17(1):26. Available from: https://doi.org/10.1186/s12977-020-00534-0

153. Primo J, Siqueira I, Nascimento MCF, Oliveira MF, Farre L, Carvalho EM, et al. High HTLV-1 proviral load, a marker for HTLV-1 associated myelopathy/ tropical spastic paraparesis, is also detected in patients with infective dermatitis associated with HTLV-1. Brazilian J Med Biol Res [Internet]. 2009 Jul [cited 2020 0ct 15]; 42(8):761-4. Available from: https:// doi.org/10.1590/S0100-879X2009005000008
154. Hisada M, Okayama A, Shioiri S, Spiegelman DL, Stuver So, Mueller NE. Risk factors for adult T-cell leukemia among carriers of human T-lymphotropic virus type I. Blood. 1998 Nov;92(10):3557-61.

155. Rosadas C, Cabral-Castro MJ, Vicente ACP, Peralta JM, Puccioni-Sohler M. Validation of a quantitative real-time PCR assay for HTLV-1 proviral load in peripheral blood mononuclear cells. J Virol Methods [Internet]. 2013 Nov [cited 2020 0ct 15]; 193(2):536-41. Available from: https://doi.org/10.1016/j.jviromet.2013.07.040

156. Cabral F, Arruda LB, Araújo ML, Montanheiro P, Smid J, Oliveira ACP, et al. Detection of human T-cell lymphotropic virus type 1 in plasma samples. Virus Res [Internet]. 2012 Jan [cited 2020 Oct 15]; 163(1):87-90. Available from: https:// doi.org/10.1016/j.virusres.2011.08.014

157. Demontis MA, Sadiq MT, Golz S, Taylor GP. HTLV-1 viral RNA is detected rarely in plasma of HTLV-1 infected subjects. J Med Virol [Internet]. 2015 Dec [cited 2020 Oct 15]; 87(12):2130-4. Available from: https://doi.org/10.1002/jmv.24264

158. Tamegão-lopes BP, Rezende PR, Cunha LM. Carga proviral do HTLV-1 e HTLV-2: um método simples através da PCR quantitativa em tempo real. Rev Soc Bras Med Trop [Internet]. 2006 nov-dez [citado 2020 out 15]; 39(6):548-52. Disponível em: https:// doi.org/10.1590/S0037-86822006000600007

159. Medeiros ACM, Vidal LRR, Von Linsingen R, Ferin AN, Strapasson TB, Almeida SM, et al. Confirmatory molecular method for HTLV-1/2 infection in high-risk pregnant women. J Med Virol [Internet]. 2018 May [cited 2020 0ct 15]; 90(5):998-1001. Available from: https://doi.org/10.1002/jmv.25014

160. Kamihira S, Yamano Y, Iwanaga M, Sasaki D, Satake M, Okayama A, et al. Intra- and inter-laboratory variability in human T-cell leukemia virus type1 proviral load quantification using real-time polymerase chain reaction assays: a multi-center study. Cancer Sci [Internet]. 2010 Nov [cited 2020 Oct 15]; 101(11):2361-7. Available from: https:// doi.org/10.1111/j.1349-7006.2010.01720.x

161. Hayden RT, Gu Z, Ingersoll J, Abdul-Ali D, Pounds $\mathrm{S}$, Caliendo AM, et al. Comparison of droplet digital PCR to real-time PCR for quantitative detection of cytomegalovirus. J Clin Microbiol [Internet]. 2013 Feb [cited 2020 0ct 15]; 51(2):540-6. Available from: https://doi.org/10.1128/jcm.02620-12 
162. Grassi MFR, Olavarria VN, Kruschewsky RA, Yamano Y, Jacobson S, Taylor GP, et al. Utility of HTLV proviral load quantification in diagnosis of HTLV-1-associated myelopathy requires international standardization. J Clin Virol [Internet]. 2013 Nov [cited 2020 0ct 15]; 58(3):584-6. Available from: https://doi.org/10.1016/j.jcv.2013.09.003

163. Kuramitsu M, Okuma K, Yamochi T, Sato T, Sasaki D, Hasegawa $\mathrm{H}$, et al. Standardization of quantitative PCR for human T-cell leukemia virus type 1 in Japan: a collaborative study. J Clin Microbiol [Internet]. 2015 Nov [cited 2020 0ct 15]; 53(11):3485-91. Available from: https://doi.org/10.1128/jcm.01628-15

164. Lee T-H, Chafets DM, Busch MP, Murphy EL. Quantitation of HTLV-I and II proviral load using real-time quantitative PCR with SYBR Green chemistry. J Clin Virol [Internet]. 2004 Dec [cited 2020 0ct 15]; 31(4):275-82. Available from: https://doi.org/10.1016/j.jcv.2004.05.016

165. Rosadas C, Tosswill JH, Tedder R, Taylor GP. Pregnancy does not adversely impact diagnostic tests for HTLV-1/2 infection. PLoS Negl Trop Dis [Internet]. 2019 Sep [cited 2020 0ct 15]; 13(9):e0007736. Available from: https://dx.doi.org/10.1371\%2Fjournal.pntd.0007736

166. Montanheiro P, Olah I, Fukumori LMI, Smid J, Oliveira ACP, Kankaki LIB, et al. Low DNA HTLV-2 proviral load among women in São Paulo City. Virus Res [Internet]. 2008 Jul [cited 2020 0ct 15]; 135(1):22-5. Available from: https://doi.org/10.1016/j.virusres.2008.01.015

167. Cook LBM, Melamed A, Demontis MA, Laydon DJ, Fox JM, Tosswill JHC, et al. Rapid dissemination of human T-lymphotropic virus type 1 during primary infection in transplant recipients. Retrovirology [Internet]. 2016 Jan [cited 2020 Oct 15]; 13:3. Available from: https://doi.org/10.1186/s12977-015-0236-7

168. Murphy EL. Infection with human T-lymphotropic virus types-1 and -2 (HTLV-1 and -2): implications for blood transfusion safety. Transfus Clin Biol [Internet]. 2016 Feb [cited 2020 0ct 15]; 23(1):13-9. Available from: https://doi.org/10.1016/j.tracli.2015.12.001

169. Ministério da Saúde (BR). Secretaria de Vigilância em Saúde. Guia de manejo clínico da infecção pelo HTLV [Internet]. Brasilia: Ministério da Saúde; 2013 [citado 2019 fev 4]. Disponível em: http://www.sierj. org.br/artigos/htlv_manual_final_pdf_25082.pdf

170. Ministério da Saúde (BR). Protocolo de uso zidovudina para tratamento do adulto com leucemia/ linfoma associado ao Vírus HTLV-1 [Internet]. Brasília:
Ministério da Saúde; 2016 [citado 2020 out 15]. Disponível em: http://www.aids.gov.br/pt-br/pub/2016/ protocolo-de-uso-da-zidovudina-para-tratamento-do-adulto-com-leucemialinfoma-associado-ao

171. Cook LB, Fuji S, Hermine 0, Bazarbachi A, Ramos JC, Ratner L, et al. Revised adult T-cell leukemia-lymphoma international consensus meeting report. J Clin Oncol [Internet]. 2019 Mar [cited 2020 0ct 15]; 37(8):677-87. Available from: https://doi.org/10.1200/jco.18.00501

172. Araujo A, Bangham CRM, Casseb J, Gotuzzo E, Jacobson S, Martin F, et al. Management of HAM/ TSP. Neurol Clin Pract [Internet]. 2020 Mar [cited 2020 0ct 15]. Available from: https:// doi.org/10.1212/CPJ.0000000000000832

173. Zihlmann KF, Alvarenga AT, Casseb J. Living invisible: HTLV-1-Infected persons and the lack of care in public health. PLoS Negl Trop Dis [Internet]. 2012 [cited 2020 0ct 15]; 6(6):e1705. Available from: https://doi.org/10.1371/journal.pntd.0001705

174. Centers for Disease Control and Prevention - CDC. Recommendations for counseling persons infected with human T-lymphotrophic virus, types I and II. MMWR [Internet]. 1993 Jun [cited 2020 0ct 15]; 42(RR-9):1-13. Available from: https://www.cdc. gov/mmwr/preview/mmwrhtml/00021234.htm

175. Coler-Reilly ALG, Yagishita N, Suzuki H, Sato $\mathrm{T}$, Araya N, Inoue E, et al. Nation-wide epidemiological study of Japanese patients with rare viral myelopathy using novel registration system (HAM-net). Orphanet J Rare Dis [Internet]. 2016 May [cited 2020 0ct 15]; 11(1):69. Available from: https://doi.org/10.1186/s13023-016-0451-X

176. Olindo S, Jeannin S, Saint-Vil M, Signate A, Edjmonana-Kaptue M, Joux J, Merle H, et al. Temporal trends in human T-lymphotropic virus 1 (HTLV-1) associated myelopathy/tropical spastic paraparesis (HAM/TSP) incidence in Martinique over 25 years (1986-2010). PLoS Negl Trop Dis [Internet]. 2018 Mar [cited 2020 0ct 15]; 12(3):e0006304. Available from: https://doi.org/10.1371/journal.pntd.0006304

177. Brant LJ, Cawley C, Davison KL, Taylor GP, the HTLV National Register Steering C. Recruiting individuals into the HTLV cohort study in the United Kingdom: clinical findings and challenges in the first six years, 2003 to 2009. Euro Surveill [Internet]. 2011 Nov [cited 2020 0ct 15]; 16(46):20017. Available from: https://doi.org/10.2807/ese.16.46.20017-en 
178. Mendoza C, Pirón M, Gonzalez R, Jiménez A, Caballero $\mathrm{E}$, Roc L, et al. Clinical presentation of individuals with human T-cell leukemia virus type-1 infection in Spain. Open Forum Infect Dis [Internet]. 2019 Jan [cited 2020 0ct 15]; 6(2):ofz036. Available from: https://oi.org/10.1093/ofid/ofz036

179. Moura AA, Mello MJG, Correia JB. Prevalence of syphilis, human immunodeficiency virus, hepatitis B virus, and human T-lymphotropic virus infections and coinfections during prenatal screening in an urban Northeastern Brazilian population. Int J Infect Dis [Internet]. 2015 0ct [cited 2020 0ct 15]; 39: 10-5. Available from: https://doi.org/10.1016/j.ijid.2015.07.022

180. Figueiró-Filho EA, Senefonte FRA, Lopes AHA, Morais 00, Souza Júnior VG, Maia TL, et al. Freqüência das infecções pelo HIV-1, rubéola, sífilis, toxoplasmose, citomegalovírus, herpes simples, hepatite B, hepatite C, doença de Chagas e HTLV I/ II em gestantes, do Estado de Mato Grosso do Sul. Rev Soc Bras Med Trop [Internet]. 2007 mar-abr [citado 2020 out 15]; 40(2):181-7. Disponível em: https://doi.org/10.1590/S0037-86822007000200007

181. Oliveira SR, Avelino MM. Soroprevalência do vírus linfotrópico-T humano tipo I entre gestantes em Goiânia, G0, Brasil. Rev Bras Ginecol 0bstet [Internet]. 2006 [citado 2020 out 15]; 28(8):467-72. Disponível em: https://doi.org/10.1590/S0100-72032006000800005

182. Olbrich Neto J, Meira DA. Soroprevalence of HTL$\mathrm{V}-\mathrm{I} / \mathrm{II}, \mathrm{HIV}$, siphylis and toxoplasmosis among pregnant women seen at Botucatu - São Paulo - Brazil: risk factors for HTLV-I/II infection. Rev Soc Bras Med Trop [Internet]. 2004 [cited 2020 Oct 15]; 37(1):28-32. Available from: https:// doi.org/10.1590/S0037-86822004000100008

183. Bittencourt AL, Dourado I, Filho PB, Santos M, Valadão E, Alcantara LC, et al. Human T-cell lymphotropic virus type 1 infection among pregnant women in northeastern Brazil. J Acquir Immune Defic Syndr [Internet]. 2001 Mar [cited 2020 Oct 15]; 26(5):490-4. Available from: https:// doi.org/10.1097/00126334-200104150-00016

184. Broutet N, Queiroz Sousa A, Basilio FP, Sa HL, Simon F, Dabis F. Prevalence of HIV-1, HIV-2 and HTLV antibody, in Fortaleza, Ceara, Brazil, 19931994. Int J STD AIDS [Internet]. 1996 Aug-Sep [cited 2020 0ct 15]; 7(5):365-9. Available from: https://doi.org/10.1258/0956462961918103
185. Santos JI, Lopes MA, Deliège-Vasconcelos E, Couto-Fernandez JC, Patel BN, Barreto ML, et al. Seroprevalence of HIV, HTLV-I/II and other perinatally-transmitted pathogens in Salvador, Bahia. Rev Inst Med Trop São Paulo [Internet]. 1995 Jul-Aug [cited 2020 0ct 15]; 37(4):343-8. Available from: https://doi.org/10.1590/S0036-46651995000400010

186. Mendes FCM, Lima JR0, Melo B0, Pinto CMFS, Maia HS, Ferro TAF, et al. Molecular detection of human T cell lymphotropic virus type 1 in pregnant women from Maranhão state, Brazil. Braz J Microbiol [Internet]. 2020 Jun [cited 2020 0ct 15]; 51(2):637-45. Available from: https://doi.org/10.1007/s42770-020-00233-0

187. Sodré Barmpas DB, Monteiro DLM, Taquette SR, Rodrigues NCP, Trajano AJB, Cunha JC, et al. Pregnancy outcomes and mother-to-child transmission rate in HTLV-1/2 infected women attending two public hospitals in the metropolitan area of Rio de Janeiro. PLoS Negl Trop Dis [Internet]. 2019 Jun [cited 2020 0ct 15]; 13(6):e0007404. Available from: https://doi.org/10.1371/journal.pntd.0007404

188. Guerra AB, Siravenha LQ, Laurentino RV, Feitosa RNM, Azecedo VN, Vallinoto ACR, et al. Seroprevalence of HIV, HTLV, CMV, HBV and rubella virus infections in pregnant adolescents who received care in the city of Belém, Pará, Northern Brazil. BMC Pregnancy Childbirth [Internet]. 2018 May [cited 2020 0ct 15]; 18(1):169. Available from: https://doi.org/10.1186/s12884-018-1753-X

189. Monteiro DLM, Taquette SR, Sodré Barmpas DB, Rodrigues NCP, Teixeira SAM, Villela LHC, et al. Prevalence of HTLV-1/2 in pregnant women living in the metropolitan area of Rio de Janeiro. PLoS Negl Trop Dis [Internet]. 2014 Sep [cited 2020 0ct 15]; 8:e3146. Available from: https:// doi.org/10.1371/journal.pntd.0003146

190. Boa-Sorte N, Purificação A, Amorim T, Assunção L, Reis A, Galvão-Castro B. Dried blood spot testing for the antenatal screening of HTLV, HIV, syphilis, toxoplasmosis and hepatitis B and C: prevalence, accuracy and operational aspects. Brazilian J Infect Dis [Internet]. 2014 Nov-Dec [cited 2020 0ct 15]; 18(6):618-24. Available from: https://doi.org/10.1016/j.bjid.2014.05.009

191. Mello MAG, Conceição AF, Sousa SMB, Alcântara LC, Marin LJ, Raiol MRS, et al. HTLV-1 in pregnant women from the Southern Bahia, Brazil: a neglected condition despite the high prevalence. Virol J [Internet]. 
2014 Feb [cited 2020 0ct 15]; 11:28. Available from: https://doi.org/10.1186/1743-422X-11-28

192. Sequeira CG, Tamegão-Lopes BP, Santos EJM, Ventura AMR, Moraes-Pinto MI, Succi RCM. Estudo descritivo da infecção pelo HTLV em uma população de gestantes do Estado do Pará, norte do Brasil. Rev Soc Bras Med Trop [Internet]. 2012 [citado 2020 out 15]; 45(4):453-6. Disponível em: https:// doi.org/10.1590/S0037-86822012005000007

193. Souza VG, Martins ML, Carneiro-Proietti ABF, Januário JN, Ladeira RVP, Silva CMS, et al. High prevalence of HTLV-1 and 2 viruses in pregnant women in São Luis, state of Maranhão, Brazil. Rev Soc Bras Med Trop [Internet]. 2012 Mar-Apr [cited 2020 0ct 15]; 45(2):159-62. Available from: https:// doi.org/10.1590/S0037-86822012000200004

194. Machado Filho AC, Sardinha JFJ, Ponte RL, Costa EP, da Silva SS, Martinez-Espinosa FE. Prevalence of infection for HIV, HTLV, HBV and of syphilis and chlamydia in pregnant women in a tertiary health unit in the western Brazilian Amazon region. Rev Bras Ginecol Obstet [Internet]. 2010 Apr [cited 2020 0ct 15]; 32(4):176-83. Available from: https:// doi.org/10.1590/S0100-72032010000400005

195. Magalhães T, Mota-Miranda AC, Alcantara LCJ, Olavarria V, Galvão-Castro B, Rios-Grassi MF. Phylogenetic and molecular analysis of HTLV-1 isolates from a medium sized town in Northern of Brazil: Tracing a common origin of the virus from the most endemic city in the country. J Med Virol [Internet]. 2008 Nov [cited 2020 0ct 15]; 80(11):2040-5. Available from: https://doi.org/10.1002/jmv.21278

196. Dal Fabbro MMFJ, Cunha RV, Bóia MN, Portela P, Botelho CA, Freitas GMB, et al. Infecção pelo HTLV 1/2: atuação no pré-natal como estratégia de controle da doença no Estado de Mato Grosso do Sul. Rev Soc Bras Med Trop [Internet]. 2008 Mar-Apr [cited 2020 0ct 15]; 41(2):148-51. Available from: https:// doi.org/10.1590/S0037-86822008000200003

197. The T and B-cell malignancy study group. The third nation-wide study on adult T-cell leukemia/ lymphoma (ATL) in Japan: characteristic patterns of HLA antigen and HTLV-I infection in ATL patients and their relatives. The T- and B-cell Malignancy Study Group. Int J Cancer [Internet]. $1988 \mathrm{Apr}$ [cited 2020 0ct 15]; 41(4):505-12. Available from: https://doi.org/10.1002/ijc.2910410406

198. Bartholomew C, Jack N, Edwards J, Charles W, Corbin D, Cleghorn FR, et al. HTLV-I serostatus of mothers of patients with adult T-cell leukemia and HTLV-I-associated myelopathy/tropical spastic paraparesis. J Hum Virol. 1998 May-Jun;1(4):302-5.

199. Hino S. Establishment of the milk-borne transmission as a key factor for the peculiar endemicity of human T-lymphotropic virus type 1 (HTLV-1): the ATL Prevention Program Nagasaki. Proc Jpn Acad Ser B Phys Biol Sci [Internet]. 2011 [cited 2020 0ct 15]; 87(4):152-66. Available from: https://doi.org/10.2183/pjab.87.152

200. Ureta-Vidal A, Angelin-Duclos C, Tortevoye P, Murphy E, Lepere JF, Buigues RP, et al. Mother-to-child transmission of human T-cell-leukemia/lymphoma virus type I: Implication of high antiviral antibody titer and high proviral load in carrier mothers. Int J Cancer [Internet]. 1999 Sep [cited 2020 Oct 15]; 82(6):832-6. Available from: https://doi. org/10.1002/(sici)1097-0215(19990909)82:6\%3C832::aid-ijc11\%3E3.0.c0;2-p

201. Oki T, Yoshinaga M, Otsuka H, Miyata K, Sonoda S, Nagata Y. A sero-epidemiological study on mother-to-child transmission of HTLV-I in southern Kyushu, Japan. Asia-Oceania J Obstet Gynaecol [Internet]. 1992 Dec [cited 2020 0ct 15]; 18(4):371-7. Available from: https://doi.org/10.1111/j.1447-0756.1992.tb00333.x

202. Takahashi K, Takezaki T, Oki T, Kawakami K, Yashiki S, Fujiyoshi T, et al. Inhibitory effect of maternal antibody on mother-to-child transmission of human T-lymphotropic virus type I. Int J Cancer [Internet]. 1991 Nov [cited 2020 0ct 15]; 49(5):673-7. Available from: https://doi.org/10.1002/ijc.2910490508

203. Ando Y, Matsumoto Y, Nakano S, Saito K, Kakimoto $\mathrm{K}$, Tanigawa T, et al. Long-term follow-up study of HTLV-I infection in bottle-fed children born to seropositive mothers. J Infect [Internet]. 2003 Jan [cited 2020 0ct 15]; 46(1):9-11. Available from: https://doi.org/10.1053/jinf.2002.1081

204. Nishijima T, Shimada S, Noda H, Miyake K. Towards the elimination of HTLV-1 infection in Japan. Lancet Infect Dis [Internet]. 2019 Jan [cited 2020 0ct 15]; 19(1):15-6. Available from: https:// doi.org/10.1016/S1473-3099(18)30735-7

205. Ishak R, Vallinoto AC, Azevedo VN, Lewis M, Hall WW, Guimarães Ishak MO. Molecular evidence of mother-to-child transmission of HTLV-IIc in the Kararao Village (Kayapo) in the Amazon region of Brazil. Rev Soc Bras Med Trop [Internet]. 2001 Nov-Dec [cited 2020 0ct 5]; 34(6):519-25. Available from: http:// dx.doi.org/10.1590/S0037-86822001000600004 
206. Silva EA, Otsuki K, Leite ACB, Alamy AH, Sa D, Vicente ACP. HTLV-II Infection associated with a chronic neurodegenerative disease: clinical and molecular analysis. J Med Virol [Internet]. 2002 Feb [cited 2020 0ct 15]; 66(2):253-7. Available from: https://doi.org/10.1002/jmv.2138

207. Catalan-Soares B, Barbosa-Stancioli EF, Alcantara LCJ, et al. HTLV-2 Horizontal and vertical transmission in a family from a Brazilian urban area: seroepidemiological, clinical and molecular study. AIDS Res Hum Retroviruses [Internet]. 2005 Jun [cited 2020 0ct 15]; 21(6):521-6. Available from: https://doi.org/10.1089/aid.2005.21.521
208. Renner JDP, Laurino JP, Menna-Barreto M, Schmitt VM. Molecular evidence of HTLV-II subtype $B$ among an urban population living in South Brazil. AIDS Res Hum Retroviruses [Internet]. 2006 Apr [cited 2020 0ct 15]; 22(4):301-6. Available from: https://doi.org/10.1089/aid.2006.22.301

209. Ishak R, Ishak MO, Azevedo VN, Santos DEM, Vallinoto ACR, Saraiva JCP, et al. Detection of HTLV-IIa blood donors in an urban area of the Amazon Region of Brazil (Belém, PA). Rev Soc Bras Med Trop [Internet]. 1998 Mar-Apr [cited 2020 0ct 15]; 31(2):193-7. Available from: http:// dx.doi.org/10.1590/S0037-86821998000200005

\section{Resumen}

El artículo está relacionado con el capítulo sobre virus linfotrópico de células $T$ bumanas (buman $T$ lymphotropic virus, HTLV) que conforma el Protocolo Clínico y Directrices Terapéuticas para la Atención Integral a Personas con Infecciones de Transmisión Sexual, publicado por el Ministerio de Salud de Brasil. La infección por HTLV-1/2 es un problema de salud pública en el mundo y Brasil tiene el mayor número de personas que viven con el virus. El HTLV-1 causa varias manifestaciones clínicas, de naturaleza neoplásica (leucemia/linfoma de células T adultas), y de naturaleza inflamatoria, como la mielopatía asociada al HTLV-1 y otras manifestaciones como la uveítis, la artritis y la dermatitis infecciosa. Estas patologías tienen una alta morbilidad y mortalidad e impactan negativamente en la calidad de vida de las personas infectadas. Esta revisión incluye información relevante para gerentes y profesionales de la salud sobre los mecanismos de transmisión viral, diagnóstico, tratamiento y monitoreo de personas que viven con HTLV-1 y 2 en Brasil.

Palabras clave: Enfermedades de Transmisión Sexual; Diagnóstico; Signos y Síntomas; Prevención de Enfermedades.

Recebido em 16/07/2020

Aprovado em 07/10/2020 